ORNL/Sub/87-SA946/05

\title{
Long-term Performance of Ceramic Matrix Composites at Elevated Temperatures: Modelling of Creep and Creep Rupture
}

July 31, 1996

Research sponsored by the U.S. Department of Energy

Office of Fossil Energy

Advanced Research and Technology Development Materials Program

Report Prepared by

W. A. Curtin, B. Fabeny, M. Ibnabdeljalil, N. Iyengar, K. L. Reifsnider Materials Response Group Department of Engineering Science and Mechanics Virginia Polytechnic Institute and State University Blacksburg, VA 24061-0219

under

Subcontract 19X-SA946C, WBS Element VPI-1

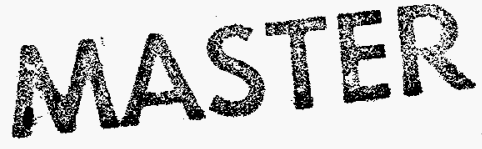

for

OAK RIDGE NATIONAL LABORATORY

Oak Ridge, TN 37831

Managed by

LOCKHEED MARTIN ENERGY RESEARCH CORPORATION

for the

U.S. DEPARTMENT OF ENERGY

under Contract No. DE-AC05-960R22464

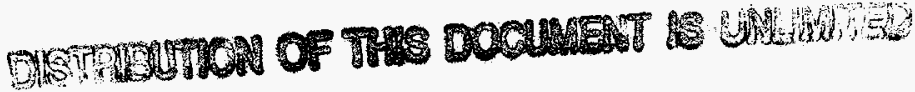




\section{DISCLAIMER}

Portions of this document may be illegible in electronic image products. Images are produced from the best available original document. 


\section{Abstract}

This Topical Report describes work to develop constitutive models for the time-dependent creep deformation and ultimate failure of ceramic composites under simple loading conditions at elevated temperatures. These models contain explicit dependences on the constituent material properties, and their changes with time, so that reliable predictions of composite performance can be made based on the expected performance of the individual components (matrix and fibers). Three critical processes in ceramic composites at elevated temperatures have been modelled.

The first process studied is creep deformation of the composite as a function of the stress and time-dependent creep characteristics of the fibers and matrix, and the failure properties of these components. General evolution formulas are derived for the relaxation time of matrix stresses and the subsequent steady-state creep rate of the composite, including the deleterious effects of fiber damage at elevated loads. Failure times are also predicted, and the model is tested against recent data on Ti-MMCs. Specific calculations on a composite of $\mathrm{Hi}-\mathrm{Nicalon}$ fibers in a Melt-infiltrated SiC matrix are presented.

The second problem addressed is creep deformation of the "interface" around broken fibers. As creep relaxes the stress carried by broken fibers, the stress carried by the remaining fibers increases and drives further fiber damage and, ultimately, composite failure. An analytic model for the interface shear stress versus time after fiber breakage allows the characteristic time scale for this phenomenon to be studied as a function of material properties. These results have then been incorporated into numerical simulations of composite failure to map out time-to-failure versus applied load for several sets of material parameters.

The third problem addressed here is probably the most crucial for current materials: the lifetime of the composite under conditions of fiber strength loss over time at temperature. Both the slow-crack growth model and the Coleman model of fiber degradation are considered, and analytic representation of the creep and rupture behavior of the composite are dervied in both cases. Simple approximate relationships are obtained between fiber life and composite life that should be a useful tool for fiber developers and testers. Strength degradation data on Hi-Nicalon fibers is then used to assess composite lifetime versus fiber lifetime for Hi-Nicalon fiber composites.

The work described here provides a comprehensive and consistent framework for the determination of composite durability versus the microscopic constituent properties of the reinforcing fibers, matrix, and interface. Although a major issue of interface oxidation is not addressed here, the present work provides a means to assess potential lifetimes of candidate materials systems if oxidative degradation can be prevented, and thus helps define the ultimate opertating limits of ceramic matrix composites at elevated temperatures. 


\section{Table of Contents}

0. Abstract

1. Introduction 1

2. Long-term Composite Performance 3

2.1. Creep of Fiber-reinforced Composites 3

2.1.1 Model Development 3

2.1.2 Application to a Metal Matrix Composite 7

2.1.3 Application to Hi-Nicalon/SiC CMC 10

2.2. Failure by Matrix/Interfacial (Shear) Creep 13

2.3. Failure by Fiber Degradation 16

2.3.1. Slow-crack growth model of fiber degradation 17

2.3.2 Coleman model of fiber degradation 21

3. Discussion 24

4. References 26

5. Appendix A: Distribution

\section{DISCLAIMER}

This report was prepared as an account of work sponsored by an agency of the United States Government. Neither the United States Government nor any agency thereof, nor any of their employees, makes any warranty, express or implied, or assumes any legal liability or responsibility for the accuracy, completeness, or usefulness of any information, apparatus, product, or process disclosed, or represents that its use would not infringe privately owned rights. Reference herein to any specific commercial product, process, or service by trade name, trademark, manufacturer, or otherwise does not necessarily constitute or imply its endorsement, recommendation, or favoring by the United States Government or any agency thereof. The views and opinions of authors expressed herein do not necessarily state or reflect those of the United States Government or any agency thereof. 
Research sponsored by the U.S. Department of Energy, Fossil Energy Advanced Research and Technology Materials Program, DOE/FE AA 1510100 Work Breakdown Structure Element VPI-1

\section{Introduction}

Ceramic Matrix Composites are currently being developed in the Fossil Energy Materials Program for use as heat exchangers, hot gas filters, and other components [1,2]. The operating conditions envisioned in these applications are both high temperatures (1200C and above) and complex chemical environments for long times, which are quite demanding. Successful material development therefore requires a detailed understanding of the deformation and failure of such composites. In particular, the relationship between the properties of the constituent materials (matrix, fiber, and interface) and the integrated composite must be established to assess the potential success of current material systems and to further optimize these systems to attain the necessary performance goals. With this in mind, we have worked to develop constitutive models for the time-dependent creep deformation and ultimate failure of ceramic composites under simple loading conditions at elevated temperatures. These models contain explicit dependences on the constituent material properties, and their changes with time, so that reliable predictions of composite performance can be made based on the expected performance of the individual components (matrix and fibers).

This topical report summarizes the accomplishments toward the above objective. We have focussed on the modelling of three critical processes in ceramic composites at elevated temperatures.

The first process is creep deformation of the composite as a function of the stress and time-dependent creep characteristics of the fibers and matrix, and the failure properties of these components. We emphasize the case in which the matrix creep is faster than the fiber creep, which is the desirable limit because matrix cracking and environmental ingress can be avoided, prolonging composite life. The major question addressed is the time for relaxation of the matrix stresses and the subsequent steady-state creep rate of the composite, including the deleterious effects of fiber damage at elevated loads. For materials in which the matrix creep is slower than that of the fibers, the characteristic times required to reach matrix cracking and, hence, environmental ingress, are also determined. General evolution formulas are given, the predictions tested against recent data on Ti-MMCs, and specific calculations for the case of Hi-Nicalon fibers in a Melt-infiltrated $\mathrm{SiC}$ matrix are presented.

The second problem addressed here is creep deformation of the "interface" around broken fibers, after the transient tensile creep behavior described above has ceased. Once tensile stresses have crept away, shear stresses remain across the fiber/matrix interface and as these relax the stress carried by broken fibers is decreased and the stress carried by the remaining fibers increases. The increasing stress drives further fiber damage and ultimately composite failure ensues at long times, after some associated creep-like behavior. We have developed an analytic model to describe the interface shear stress versus time after fiber breakage which allows the characteristic time scale for this 
phenomenon to be studied as a function of material properties. The results have then been incorporated into numerical simulations of composite failure to map out time-to-failure versus applied load for several sets of material parameters. In general, "interface" relaxation is a long-time degradation mechanism which may not be important (due to faster life-limiting mechanisms) in materials with matrices creeping faster than the fibers. However, improved fibers may ultimately succumb to such a degradation mechanism and so it is necessary to assess such limiting lifetimes.

The final problem addressed is probably the most crucial for current materials: the lifetime of the composite under conditions of fiber strength loss over time at temperature. Considerable data has been obtained recently by the NASA and Penn State groups on the degradation of various fibers at elevated temperatures and various atmospheres, tested in the laboratory at convenient gauge lengths. What is the composite lifetime given such fiber data? The answer is not trivial because the rule-of-mixtures does not strictly apply to ceramic composites; the composite failure depends on accumulated fiber damage at a critical gauge length different from that investigated in the laboratory. Large differences in the failure time between individual fibers and composites can arise depending on the constituent material properties. We have carried out two sets of mechanistically-based calculations to address this issue. In the first, we adopt the slow-crack growth model of fiber degradation and develop an analytic representation of the creep and rupture behavior of the composite. In the second, we adopt the generalized Coleman model of fiber strength degradation in time. In both cases, simple approximate relationships are obtained between fiber life and composite life that should be a useful tool for fiber developers and testers. We then use strength degradation as measured by NASA to assess composite lifetime versus fiber lifetime for Hi-Nicalon fibers at various applied loads. The two modelled degradation mechanisms give similar life predictions for the same experimental fiber data, indicating that the detailed fiber strength loss mechanism is not critical to a basic understanding of the composite degradation. For Hi-Nicalon fibers the predicted composite lifetimes are about 4-20 times longer than the typical fiber lifetimes at laboratory gauge lengths, depending on load levels and specific degradation mechanism.

None of the above models account for the oxidative degradation of the fiber/matrix interface. This problem is the major one facing CMC materials designers but is difficult to incorporate into models of composite fracture. The reason for the difficulty is that loss of the interface restores strong fiber/matrix bonding, which in turn drives brittle or monolithic-like failure. Such failure must be treated using appropriately modified fracture mechanics considerations and does not depend on, for instance, explicit fiber strength loss. The calculations and predictions presented here are thus applicable for longer-term planning of composite design. The interface oxidation problem must be solved by appropriate system design and chemical inhibition, and once overcome the mechanisms of degradation discussed here will become of paramount importance. The results obtained here can thus be considered to define ultimate operating limits of the materials. If these limits are not acceptable for specific applications then further material optimization or changes will be needed in the future even if the immediate short-term failure problems are solved.

In the following Section, we describe each of the above accomplishments, while Section 3 provides a brief summary and discussion of our major results. 


\section{Long-term Composite Performance}

\subsection{Creep of Fiber-reinforced Composites}

\subsubsection{Model Development}

Here we examine the time-dependent deformation of composites reinforced with continuous fibers which exhibit successive, stochastic fragmentation under increasing applied load. We present a simple one-dimensional model of a viscoelastic-plastic matrix reinforced with continuous viscoelastic fibers aligned parallel to an axis of tensile loading in a manner identical to the model of McLean [3]. In addition, we incorporate the effects of fiber damage using a non-linear constitutive model of the fiber bundle deformation which includes the stochastic failure of fibers and the influence of fiber/matrix slip around fiber breaks. We then present detailed quantitative analyses of the case particularly applicable to ceramic composites: a viscoelastic-plastic matrix reinforced with viscoelastic fibers and subjected to a step tensile loading. To test the model, we compare numerical solutions of our model to experimental data on Titanium Matrix Composites recently obtained by Weber, Du and Zok [4], and find reasonable agreement in the creep rates, failure times, and general deformation history. We then predict the evolution of creep strain and fiber damage in a $\mathrm{Hi}-\mathrm{Nicalon} / \mathrm{Melt}$-infiltrated $\mathrm{SiC}$ composite at $1200 \mathrm{C}$ to demonstrate the intrinsic time scales for stress relaxation.

We are concerned with the time evolution of the average axial components of stress and strain in a composite subjected to a uniaxial tensile loading and uniaxiallyreinforced by a volume fraction $f$ of continuous viscoelastic fibers of radius $r$ which are aligned parallel to the axis of loading. We consider viscoelastic-plastic matrix and fibers which exhibit the constitutive relationships

$$
\dot{\varepsilon}_{m}=\frac{\dot{\sigma}_{m}}{E_{m}}+G \sigma_{m}^{q}, \quad \dot{\varepsilon}_{f}=\frac{\dot{\sigma}_{f}}{E_{f}}+H \sigma_{f}^{p}
$$

Here, $\varepsilon_{m}$ is the axial strain in the matrix, and $\sigma_{m}$ is the axial stress in the matrix. $\varepsilon_{f}$ and $\sigma_{f}$ are the respective quantities for the unbroken fibers, and a superscribed dot indicates a derivative with respect to time. Eq. 1 applies when $\sigma_{m}<\sigma_{m c}\left(\sigma_{m c}=\right.$ cracking stress of the matrix). When $\sigma_{m}=\sigma_{m}$, the matrix cracks irreversibly and so $\sigma_{m}=0$ is then assumed. $E_{f}$ and $E_{m}$ are the Young's modulus of the fibers and matrix, respectively. $G$ and $q$, and $H$ and $p$, are parameters that characterize the inelastic behavior of the matrix and fibers, respectively, which exhibit power law creep behavior. The mechanical analogue of Eq. 1 is a linear spring connected in series with a nonlinear dashpot, which resembles the linearly viscoelastic Maxwell material. Eq. 1 does not account for a distinct primary creep regime or time-dependent recovery. More general creep relations with specific time dependence can be considered, and will be utilized to represent the Hi-Nicalon fibers discussed below.

We assume that structural integrity of the composite is maintained so that 


$$
\varepsilon_{m}(t)=\varepsilon_{f}(t)
$$

for all time $t$. This implies that the strain rates, Eqs. 1, in both the constituents are equal for all time $t$. Load conservation across an arbitrary cross-sectional plane of the composite implies that

$$
\sigma_{a p p}(t)=(1-f) \sigma_{m}(t)+\sigma_{f-\text { total }}(t)
$$

for all time $t$. Here, $\sigma_{\text {app }}$ is the applied stress and $\sigma_{f \text {-total }}$ is the total stress supported by the fiber bundle at the cross-section under consideration.

The fiber "bundle" consists of fibers that are broken at various locations. We consider those composite materials in which the fiber/matrix interface is either debonded upon matrix cracking or fiber cracking, such that after fiber breaking the fiber slips relative to the matrix as governed by a constant shear stress $\tau$ across the slipped portion of the interface. This shear stress across the fiber-matrix interface allows for load to be transferred back into fibers that are broken. The recovery length required for the stress in a broken fiber to rise from a value of zero at a break to the stress it would support if unbroken, $\sigma_{f}$ is $l_{f}$. Thus, regions of fiber within $l_{f}$ of a break still carry some tensile load between 0 and $\sigma_{f}$. Considering any arbitrary cross-section of the composite, the quantity $\sigma_{f-\text { towal }}$ is therefore the sum of the stresses carried by fibers that have breaks that are farther than $\pm l_{f}$ from that cross-sectional plane and by fibers that have breaks within $\pm l_{f}$ of that cross-sectional plane. The first group of fibers are considered to be "unbroken", and are subjected to the stress $\sigma_{f}$, while the fibers of the last group support a range of lesser stresses according to the exact location of any breaks in the fibers that are within $\pm l_{f}$ of the cross-sectional plane. In a detailed analysis Curtin [5] showed that if (i) the fraction of fibers that have more than one break within $\pm l_{f}$ of the cross-sectional plane is relatively small, (ii) there are no stress concentrations in fibers adjacent to broken fibers (i.e. the fibers exhibit global load-sharing), and (iii) the finite population of fiber strengths is adequately described via a Weibull distribution, then

$$
\sigma_{f-\text { total }}(t) \approx\left(1-\frac{1}{2}\left(\frac{\max _{-\infty} \sigma_{f}(s)}{\sigma_{c}}\right)^{m+1}\right) f \sigma_{f}(t),
$$

for all time $t$. The characteristic strength appearing in Eq. 4 is

$$
\sigma_{c}=\left(\frac{\sigma_{0}^{m} L_{0} \tau}{r}\right)^{\frac{1}{(m+1)}}
$$


In Eq. $5, \sigma_{0}$ is the characteristic strength of the Weibull strength distribution of fibers tested at gauge length $L_{0}$, and the Weibull shape parameter $m$ describes the variability in fiber strengths. The characteristic strength $\sigma_{\mathcal{C}}$ is the fiber strength at the critical gauge length

$$
\delta_{c}=r \sigma_{c} / \tau
$$

The nonlinear damage law of Eq. 4 is the main ingredient of our damage-based creep rupture model. The non-linear term in brackets accounts for the probability of fiber damage within a slip length $l_{f}$ for fibers under remote load $\sigma_{f}$, and for the average reduced stress carried by such broken fibers. The applicability of this damage formulation law has been previously demonstrated for time-independent uniaxial tensile strength in both ceramic and metal matrix composites.

It can now be made clear why the creep relation for the fibers depends on $\sigma_{f}$ rather than on $\sigma_{f-t o t a l}$. The quantity $\sigma_{f}$ is the stress on the portions of the fibers which are not sliding relative to the matrix, and hence $\sigma_{f}$ is directly proportional to the elastic fiber strain in the composite, and creep deformation only occurs in these same portions and is controlled by $\sigma_{f}$. The quantity $\sigma_{f-\text { total }}$ contains the additional stress carried by the broken portions of the fiber bundle, but these regions of fiber respond by slip to any deformations imposed by either creep or additional applied loads.

In total, Eqs. 1-4 constitute a closed system of algebraic and differential equations for the history of $\sigma_{f}$ which can be solved when the history of the applied stress or strain is known. Here, we subject the composite to a step tensile loading defined by

$$
\sigma_{a p p}(t)=\left\{\begin{array}{cc}
0 & t \leq 0 \\
\sigma_{a p p} & t>0
\end{array},\right.
$$

where $\sigma_{a p p}>0$. We find it advantageous to define the scaled, nondimensional variables

$$
\hat{\sigma}_{f}=\frac{\sigma_{f}}{\sigma_{c}} ; \hat{\sigma}_{a p p}=\frac{\sigma_{a p p}}{\sigma_{c}} ; \hat{\sigma}_{m y}=\frac{\sigma_{m y}}{\sigma_{c}} ; \hat{t}=E_{m} G \sigma_{c}^{\alpha-1} t \text {. }
$$

The choice of $\sigma_{C}$ as the unit of stress is made because of its appearance in the damage law; it is not related to any characteristic matrix stress. In most cases of interest, $\sigma_{c}$ is much larger than any stress sustainable by the matrix; thus the characteristic dimensionless times which arise in applications are usually on the order of $\left(\sigma_{c} / \sigma_{m c}\right)^{q-1} \gg 1$.

Combining Eqns. 1-4, we obtain the rate of change of stress in the unbroken portions of the fibers as

$$
\frac{d \hat{\sigma}_{f}}{d \hat{t}}(\hat{t})=\frac{\left(\hat{\sigma}_{a p p}-f \hat{\sigma}_{f}(\hat{t})+\frac{f}{2}\left(\hat{\sigma}_{f}(\hat{t})\right)^{m+2}\right)^{q}-\frac{H\left(\sigma_{c}\right)^{p-q}(1-f)^{q}}{G}\left(\hat{\sigma}_{f}(\hat{t})\right)^{p}}{(1-f)^{q-1}\left(\frac{E_{c}}{E_{f}}-\frac{f(m+2)\left(\hat{\sigma}_{f}(\hat{t})\right)^{m+1}}{2}\right)},
$$

for all time $\hat{t}>0$. 
As an aside, if the composite was not susceptible to fiber fracture or fiber creep, and was loaded in the same manner, the equation governing the evolution of fiber stress for all time $\hat{t}>0$ would be simply

$$
\frac{d \hat{\sigma}_{f}}{d \hat{t}}(\hat{t})=\frac{\left(\hat{\sigma}_{a p p}-f \hat{\sigma}_{f}(\hat{t})\right)^{q}}{\frac{E_{c}(1-f)^{q-1}}{E_{f}}},
$$

which can be integrated analytically to obtain the deformation; this is essentially McLean's model for the creep of fiber-reinforced composites. Comparing with Eq. 9, we see that fiber damage always leads to higher stresses on the unbroken fibers, and greater composite creep rates, but that the transfer of stress onto the fibers is slowed by the creeping deformation of the fibers themselves.

The initial conditions for Eq. 9 are as follows. If the matrix does not crack initially (small applied loads), i.e. if $\hat{\sigma}_{a p p} \leq \frac{\hat{\sigma}_{m c} E_{c}}{E_{m}}$, then

$$
\hat{\sigma}_{m 0}=\frac{E_{m} \hat{\sigma}_{a p p}}{E_{c}} \text {. }
$$

If the matrix undergoes cracking on the initial loading then $\hat{\sigma}_{m 0}=0$. With the appropriate value for $\hat{\sigma}_{m 0}$, the initial fiber stress $\hat{\sigma}_{f 0}$ is the solution of

$$
\hat{\sigma}_{a p p}=(1-f) \hat{\sigma}_{m 0}+\left(1-\frac{1}{2}\left(\hat{\sigma}_{f 0}\right)^{m+1}\right) f \hat{\sigma}_{f 0}
$$

$\hat{\sigma}_{f 0}$ is not simply equal to $\frac{\hat{\sigma}_{a p p} E_{f}}{E_{c}}$, for that would imply that no fibers break initially, regardless of the magnitude of the applied stress. Finally, because the fiber stress has a maximum value governed by the damage law, no solution to Eq. (12) exists if the applied stress exceeds the "fast-fracture" ultimate tensile strength of the composite:

$$
\hat{\sigma}_{u t s}=f\left(\frac{m+1}{m+2}\right)\left(\frac{2}{m+2}\right)^{\frac{1}{m+1}} .
$$

If the applied stress is larger than this value then the composite fails immediately upon loading.

We discuss here the (generally optimal) case in which the fiber creep rate is slower than that of the matrix. Then, the matrix gradually relaxes by creeping and load is transferred to the (damaging) fiber bundle; the matrix does not undergo matrix cracking if it survives the initial applied load, thereby protecting the fibers from external environmental ingress. The stress in the matrix does not decay to zero as $t \rightarrow+\infty$, but rather to a value at which the matrix and fibers creep at the same rate, and hence the composite never ceases to creep. The total creep strain versus time is obtained by integrating Eq. 9 numerically to get $\sigma_{f}(t)$ and substituting the result into Eq. 1 to obtain the creep rate, and then integrating Eq. 1 over time. In all cases, after some initial 
transient behavior, the composite tends toward a steady-state creep rate $\dot{\varepsilon}_{\infty}=H \sigma_{f o n}^{p}$, where the long-time fiber stress $\hat{\sigma}_{\text {foo }}$ is the solution to

$$
\left(\hat{\sigma}_{a p p}-f \hat{\sigma}_{f o}+\frac{f}{2}\left(\hat{\sigma}_{f o}\right)^{m+2}\right)^{q}-\frac{H\left(\sigma_{c}\right)^{p-q}(1-f)^{q}}{G}\left(\hat{\sigma}_{f o}\right)^{p}=0 .
$$

Although some fibers break, which influences the overall creep rate, the damaged fiber bundle is still able to carry the entire applied load.

In ceramic matrix composites under fast loading conditions, the matrix generally cracks well prior to composite failure and thus the composite strength is the bundle strength of the fibers alone. In such a situation, then, the present model predicts that a ceramic composite will either (i) fail instantly on loading, if the applied stress is above the fast-fracture strength, or (ii) will have an infinite life with some steady-state creep rate after an initial transient period, if the applied stress is below the fast-fracture strength. Therefore, creep redistribution of applied tensile loads does not cause failure in CMCs. In practice, of course, several additional effects cause time-dependent rupture in CMCs: creep relaxation of the interfacial sliding stress (which occurs on a much longer time scale then the tensile stress relaxation) and fiber strength degradation. We will discuss these below, and here only note that the present theory is particularly useful for predicting the evolution of creep strain and load transfer between fibers and matrix under conditions when fiber strength degradation occurs over a longer time scale then the tensile creep relaxation.

\subsubsection{Application to a Metal-Matrix Composite}

To demonstrate the general applicability of the model for predicting composite creep rates and failure, and thereby validate some underlying assumptions, we apply the model to predict the response of Titanium-matrix composites. Data on a Ti-6Al-4V alloy matrix reinforced by a 0.32 volume fraction of continuous, aligned SiC fibers (BP Sigma) to a constant tensile stress and constant strain rate loadings at $600^{\circ} \mathrm{C}$ has been obtained by Weber, Du, and Zok [4]. Although not a CMC, the same general principles of deformation and strength apply here, with the simplification that the creep rate of the fibers is negligible $(\mathrm{H}=0$ in Eq. 1$)$. In addition, matrix yielding occurs at elevated loads rather than matrix cracking, which adds an additional load-carrying capability of (1-f) $\sigma_{m y}$ to the composite strength. In this case, there is thus a load range between the fiber bundle strength of Eq. 13 and the UTS of the MMC, which is higher by $(1-f) \sigma_{m y}$, in which failure can occur by creep-driven transfer of load from the matrix to the fibers.

By extracting fibers from the as-processed composite and by analyzing the transverse tensile creep of the composite, Weber, $\mathrm{Du}$, and Zok determined that the constituent parameters at $600 \mathrm{C}$ were as follows: 
Fibers: $E_{f}=360 \mathrm{GPa} ; \mathrm{r}=50 \mu \mathrm{m}$

$$
\sigma_{0}=1470 \mathrm{MPa} ; L_{0}=1 \mathrm{~m} ; m=5
$$

$$
\text { Matrix: } \begin{aligned}
E_{m} & =71.76 \mathrm{GPa} ; \sigma_{m y}=280 \mathrm{MPa} \\
G & =4.12 \cdot 10^{-31} \mathrm{~Pa}^{-3} \mathrm{~s}^{-1} ; q=3
\end{aligned}
$$

$$
\text { Interface: } \tau=20 \mathrm{MPa}
$$

With these values, the characteristic fiber stress and composite UTS are then

$$
\sigma_{c}=3742 \mathrm{MPa} \quad ; \quad \sigma_{u t s}=1023 \mathrm{MPa}
$$

including the matrix yield stress contribution to the UTS. The stress below which no failure can occur, the fiber bundle strength, is $833 \mathrm{MPa}$. The strain at which the fiber bundle fails is calculated to be $0.844 \%$.

A second composite was heat-treated in air at $600{ }^{\circ} \mathrm{C}$ for 100 hours, and the fibers were then removed by matrix dissolution and tested in tension. The heat treatment caused growth in the flaws present in the fibers, and weakened them in a fairly uniform manner, such that after 100 hours at temperature

$$
\sigma_{o}=1290 M P a ; L_{o}=1 m ; m=5 \text {. }
$$

If these values are taken as the fiber strength distribution, then the corresponding characteristic stress is $\sigma_{c}=3356 \mathrm{MPa}$, the "fast-fracture" strength is $937 \mathrm{MPa}$ (although not really relevant to fast-fracture, of course), the stress below which no failure occurs is then $747 \mathrm{MPa}$, and the characteristic fiber bundle failure strain is $0.75 \%$. Since the present model does not incorporate such degradation of fiber strength occuring over time scales relevant to creep in an actual composite at high temperatures, we have indirectly examined the effect of this phenomena by predicting response of composites reinforced by the two fiber strength distributions, as-processed and heat-treated. We expect the results from these two cases to bracket the measured response of the test specimens over the time scale of 100 hours.

Using the values given in (15), the initial-value problem given by Eqns. 7-9 was integrated numerically, and the predicted deformation behavior compared to the experimental data at applied stresses of 750,800 and $850 \mathrm{MPa}$. The measured and predicted strains versus time are shown in Figure 1; the predicted deformation is in rather good agreement with the data at early and intermediate times for the as-processed fiber strength values. At longer times, the discrepancy in strain grows for $750 \mathrm{MPa}$ but the agreement using the 100 hour fiber strengths is quite good. These results validate the general model we have developed.

The deviation between predicted and observed strains relative at $850 \mathrm{MPa}$ even at short times is rather surprising, as is the short lifetime. One rationalization of this result is that perhaps this particular specimen contained initial fiber damage or permanent fiber 


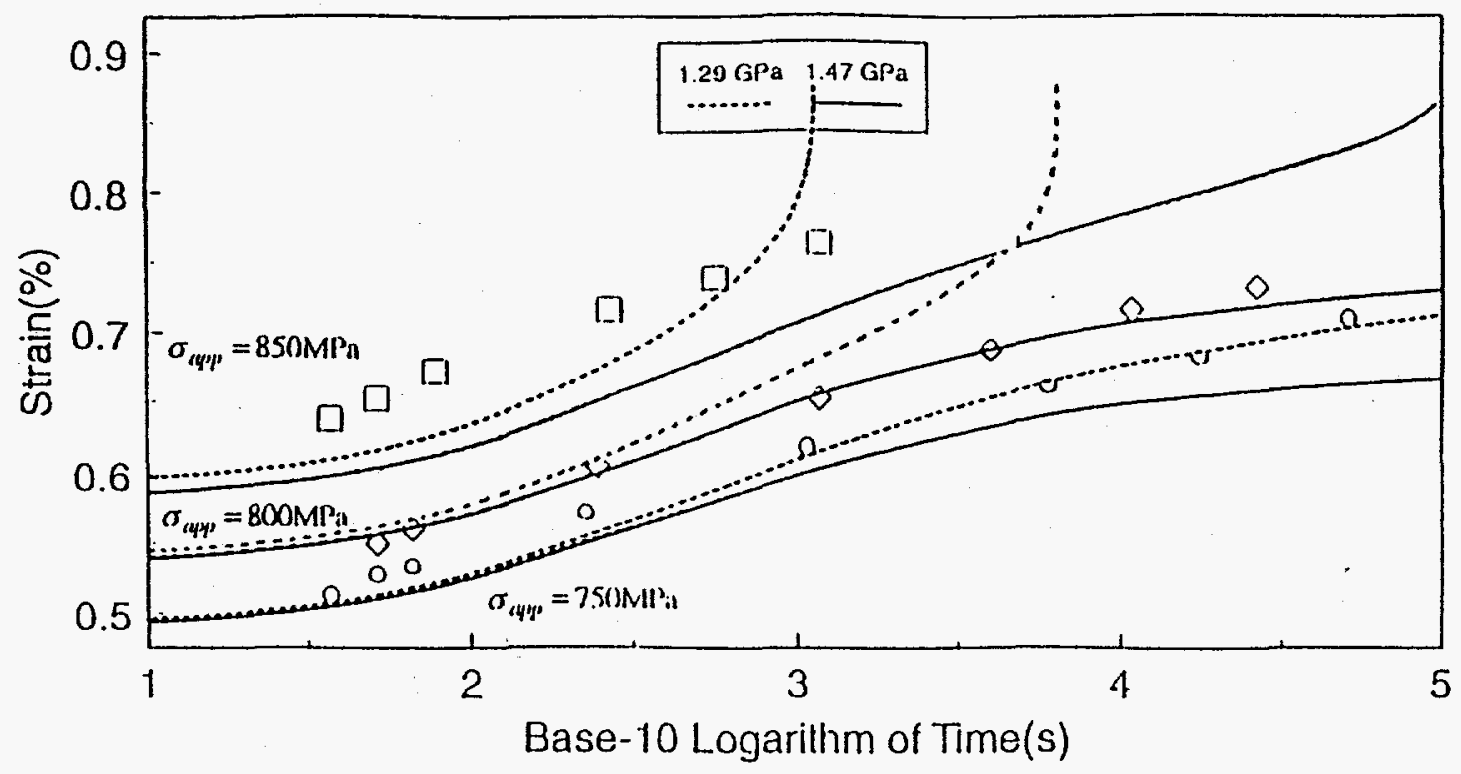

Figure 1. Creep strain versus time for a Titanium matrix composite at applied stresses of 750,800 , and $850 \mathrm{MPa}$. Open symbols - data of Weber et al. (Ref. 4); solid lines predictions using as-processed fiber strengths; dashed lines - predictions using heat-treated fiber strengths.

bending, both phenomena commonly induced during processing of such metal matrix composites. Initial damage or bending reduces the tensile strength, an issue well studied by Wadley and coworkers. It also leads to enhanced strain at time $t=0$, and an increased creep rate and shorter life compared to the present predictions. The incorporation of fiber damage and bending, as discussed by Duva et al. [6], into the present model can be accomplished by an appropriately modified fiber damage law.

Figure 2 shows the predicted tensile failure time as a function of applied stress (although plotted in the traditional manner of stress versus time), along with the observed failure times as measured on samples of $1^{\prime \prime}$ and $4^{\prime \prime}$ gauge length. At short times, the predicted fast fracture strength is actually lower than the measured value of $1120 \mathrm{MPa}$ on $1^{\prime \prime}$ gauge length composite samples, and comparable to that of the $4^{n}$ gauge length samples. The general trend of rapidly increasing lifetime with small decreases in applied stress is roughly captured, and nearly over the correct range of stresses. The predicted results using the two different fibers strengths do nearly bracket all of the measured lifetimes versus stress over both sample gauge lengths, and hence part of the steeper decline in strength with time may be attributable to the fiber degradation, although the time dependence of the fiber degradation is currently unknown. 


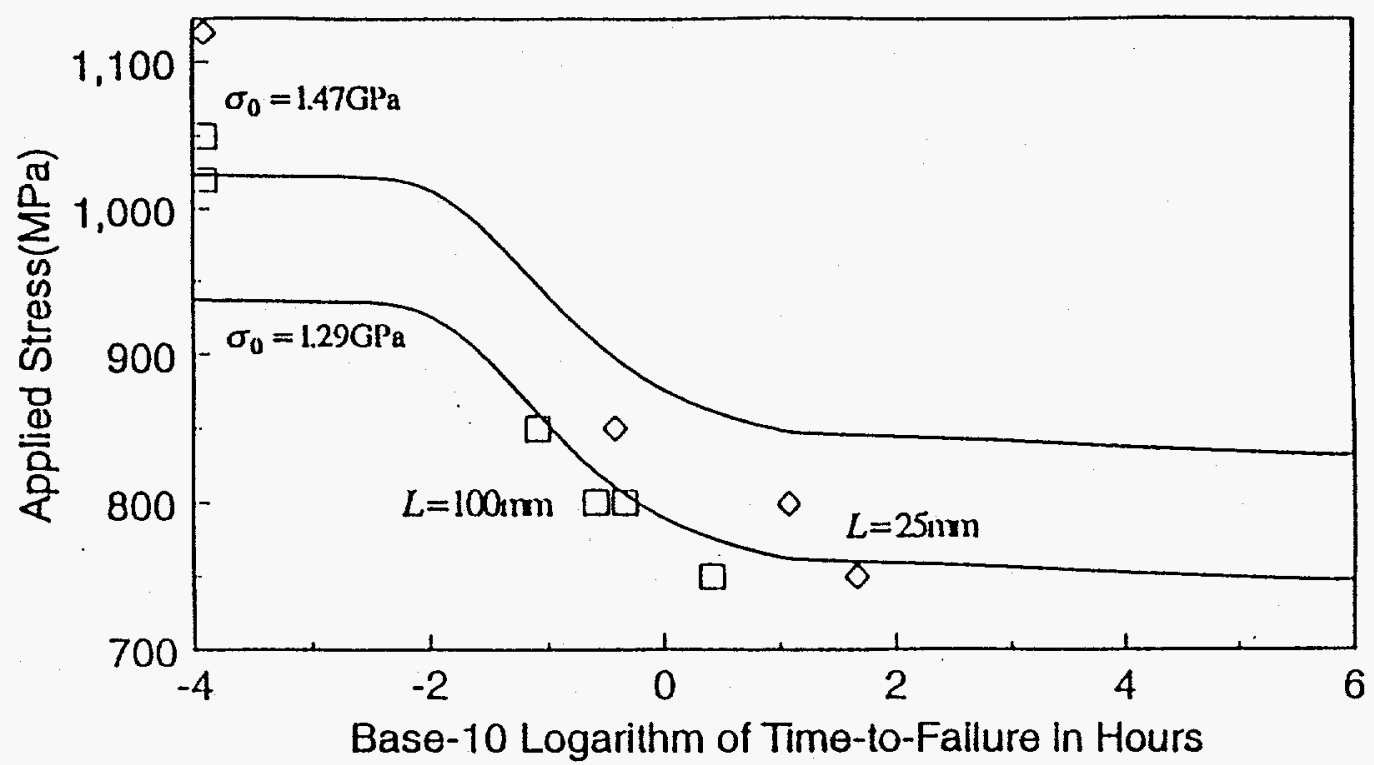

Figure 2. Applied stress versus composite lifetime for a Titanium matrix composite. Open symbols - data from Weber et al. at I" (triangles) and 4" (squares) gauge lengths; solid lines - predictions for as-processed and heat-treated fiber strength distributions.

\subsubsection{Application to a Hi-Nicalon/Melt-infiltrated SiC CMC}

Here we apply the model of Sec. 2.1.1 to predict the deformation in a ceramic matrix composite composed of woven mats of Hi-Nicalon fibers embedded in a Meltinfiltrated $\mathrm{SiC}$ matrix, with $40 \%$ volume of fibers, at $1200 \mathrm{C}$, and under various uniaxial loadings. Since the transverse fibers do not play any appreciable role in the deformation or failure process, we consider this material to be adequately represented by a uniaxial material with $f=0.20$ volume fraction of fibers in the loading direction. The Meltinfiltrated matrix is selected because some creep data is available, whereas the creep behavior for CVI Silicon Carbide, a primary matrix material in the Fossil Energy Program, is not well-established at present.

The creep behavior of Hi-Nicalon have been determined by DiCarlo et al. [7] and characterized by the general form

$$
\dot{\varepsilon}_{f}=A p \sigma^{n}\left(t+t_{0}\right)^{p-1} \exp (-p Q / R T)
$$


which exhibits continuous "hardening" or decreasing creep with increasing time for $p<1$. We have added an additional offset time $t_{0}$ to the original equation of DiCarlo et al. because their original result yields an infinite creep rate at time $t=0$ which is not physically possible. The offest time is determined such that at $t=0$ the fiber creep and the matrix creep are equal. This $t_{0}$ is generally a short time (on the order of minutes to a few hours) relative to the major creep deformation times and does not affect our results in any important physical way. Finally, although the DiCarlo et al. form includes primary creep relaxation for which the assumption of superposition implicit in our model cannot be formally justified, we utilize our creep evolution model to estimate the major consequences of stress redistribution on the creep deformation of these materials.

The melt-infiltrated matrix is assumed similar to that tested by Weiderhom et al. [8], which exhibits a power-law rate similar to Eq. 1 with the prefactors $G=1 \times 10^{-39} /(s-$ $\mathrm{Pa}^{4}$ ) and $\mathrm{q}=4$ for stress lower than about $150 \mathrm{MPa}$. Other relevant constitutive properties of the fibers, matrix and interface at the $1200 \mathrm{C}$ temperature were taken as

$$
\text { Fibers: } \begin{aligned}
& E_{f}=300 \mathrm{GPa} ; \mathrm{r}=7.5 \mu \mathrm{m} \\
& \sigma_{0}=2000 \mathrm{MPa} ; L_{0}=1 \text { inch } ; m=5
\end{aligned}
$$

$$
\begin{aligned}
& \text { Matrix: } E_{m}=300 \mathrm{GPa} ; \sigma_{m}=250 \mathrm{MPa} \\
& \text { Interface: } \tau=10 \mathrm{MPa}
\end{aligned}
$$

For these values, the fast-fracture composite strength at temperature is $458 \mathrm{MPa}$. We consider applied stresses at lower values, and explicitly lower than the (estimated) matrix cracking stress. At such low loads, the extent of fiber damage is not too large and has fairly small effects on the overall deformation history. Thus, the assumed fiber strength parameters will not have a critical effect on the general trends of the results.

The evolution of stress in the fibers during creep follows an equation similar to Eq. 9 but the second term in the numerator, associated with the fiber creep, is modified to account for the different form of the fiber creep rate used for these fibers. The evolution equation is integrated numerically and the combined with the creep law itself to obtain the creep strain in the composite, and stresses in the fibers and the matrix, versus time. Results for three different stress levels of $100 \mathrm{MPa}, 140 \mathrm{MPa}$, and $200 \mathrm{MPa}$, are shown in Figure 3. Interestingly, the time scale for stress relaxation and creep is fairly long, so that it is inappropriate to estimate creep life simply by considering the fiber creep rate at an effective applied stress of $\left(\sigma_{\mathrm{app}} / \mathrm{f}\right)$; the "primary" portion of the creep is extensive. This behavior is obtained because the fiber and matrix creep rates are not too different at short times and so the transfer of stress from matrix to fibers occurs only very slowly as the fibers creep harden. The $q=4$ exponent for the matrix creep also implies that the creep rate does slow down significantly as the matrix stress drops only moderately, which also contributes to the prolonged creep region.

The time required for $1 \%$ creep deformation, a common design limit, is evident in Figure 3. The $1 \%$ creep life of the composite is on the order of several hundred hours (625 hours at $140 \mathrm{MPa}$ ) and complete transfer of stress from matrix to fibers has not 


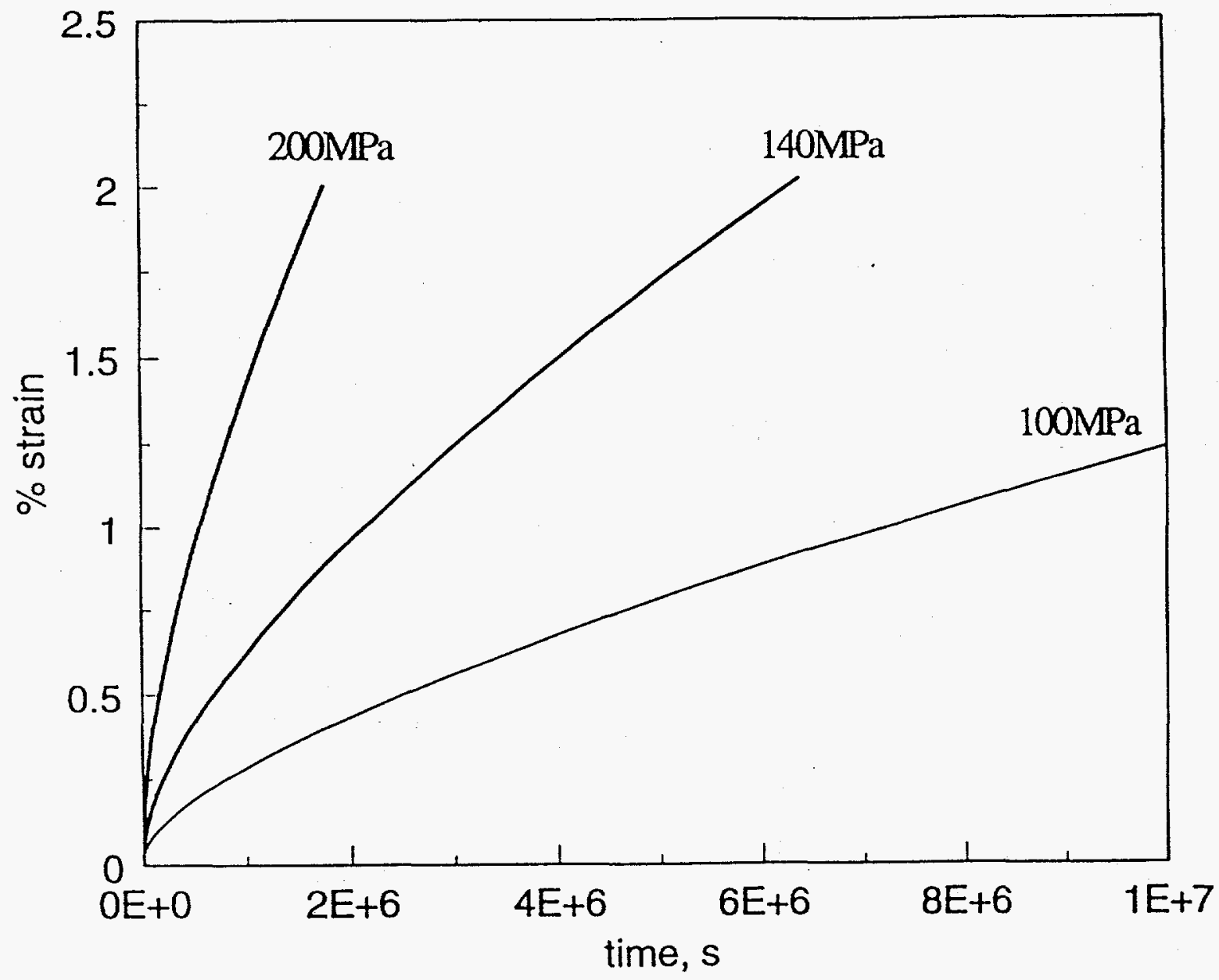

Figure 3. Strain versus time for Hi-Nicalon/Melt-infiltrated CMC as predicted by the present model at various applied loads. Note that transfer of stress from matrix to fibers occurs gradually. The time to obtain $1 \%$ creep strain is on the order of a few hundred hours in this stress range.

occurred within this time. The estimated creep life from Eq. 18 for the fibers alone, and assuming the fibers carry a load of $\sigma_{\mathrm{app}} / \mathrm{f}$ starting from $\mathrm{t}=0$, is only 99 hours at $140 \mathrm{MPa}$, quite a bit smaller than the values predicted here. Thus, the present analysis should be used to obtain realistic rather than overly-conservative estimates of creep life.

The low stresses on the fibers during this "transient" regime also have implications for stress rupture. Since the fiber strength degradation rate is very sensitive to stress level (see below), the low stresses during the transient creep regime slow down the rate of fiber degradation relative to the rate that would prevail at an effective stress of $\left(\sigma_{\mathrm{app}} / \mathrm{f}\right)$. 


\subsection{Creep and Failure via Interfacial Shear Stress Relaxation}

Once a loaded composite has reached a "steady-state" condition at which the matrix tensile stresses have been decreased to near zero and the fiber bundle is carrying essentially all of the load, other longer-term deformation modes can be manifest. Here, we consider relaxation of the shear stress across the fiber/matrix interface around those fibers which have broken. The general scenario of deformation is as follows. When a fiber breaks, the fiber/matrix $(\mathrm{f} / \mathrm{m})$ interface is debonded (if not already debonded by matrix cracking) and the matrix slides relative to the fibers subject to the constraint of the residual frictional sliding stress $\tau$ along the interface. The matrix in the vicinity of this broken fiber is thus subject to a shear stress $\tau$ at the $\mathrm{f} / \mathrm{m}$ interface and the matrix can relax this stress by creep. A decrease in the shear stress then implies that there is additional slip along the fiber to maintain the axial equilibrium condition away from the break. The slip length along the fiber is $l_{f}(t)=r \sigma_{f} / 2 \tau(t)$ if the far-field fiber axial stress is $\sigma_{f}$ and the shear stress is a function of time. As shear decreases and slip increases, the broken fibers carry less and less "pullout" load and over longer and longer gauge lengths. This decrease in load carrying capability implies an increasing stress on the remaining unbroken fibers. Eventually, some of these fibers will then also break, initiating shear relaxation around their perimeters and increasing even further the stresses on the remaining intact fibers. This process of breakage, slipping, relaxation, and further breaking culminates in rupture of the material after a sufficient amount of damage and relaxation has occurred. This process is described in more complete detail below.

Before the composite degradation can be studied numerically or analytically, it is clear that a form for the interfacial shear stress along a broken fiber and versus time is obtained that incorporates the shear creep behavior of the matrix and the slip along the fiber/matrix interface. Such a shear stress must also be expressible in a closed form so that it can easily be employed in the numerical simulations. Du and McMeeking [9] have recently addressed the problem of matrix shear stress relaxation around a broken fiber in a composite, and have derived a differential equation for the axial fiber displacement $u(z, t)$ as a function of position away from the fiber break and time. Their result is

$$
-\frac{1}{w} \frac{d u(z, t)}{d t}=\frac{1}{G_{m}} \frac{d \tau}{d t}+3^{\frac{m t}{2}} G \tau^{n}
$$

where $G_{m}$ is the matrix shear modulus and $w$ is the fiber spacing. Unfortunately, full solutions of this differential equation are not obtainable analytically and moreover the resulting shear stress is explicitly dependent on the axial location $z$.

Numerical solutions for various cases by $\mathrm{Du}$ and McMeeking demonstrate that the shear stress is only very weakly dependent on $z$, and this motivates us to consider a simplifying approximation which yields a solvable differential equation for a $\mathrm{z}$-independent shear stress. Specifically we envision that because the fiber is free at the broken end, the displacement of the slipping part of the fiber occurs in a rigid manner and the magnitude of the displacement is controlled by the displacement at the end of the slip zone $z=l_{f}$ where strain compatability with the matrix is established. Mathematically, this is expressed by the condition 


$$
\dot{u}(z, t)=\dot{l}_{f} \varepsilon_{c}
$$

where $\varepsilon_{\mathrm{c}}$ is the composite strain. Kelly and Street used the more restricted integrated form of this displacement law, $u_{f}=l_{f} \varepsilon_{c}$, in early work on the deformation of discontinuously reinforced composites [10]. Using the relationship between slip length $\mathrm{l}_{\mathrm{f}}$ and $\tau$, and substituting the above ansatz into the differential equation above, leads to a $z-$ independent equation for $\tau(\mathrm{t})$ :

$$
\frac{r \sigma_{a p p}^{2}}{2 w f E_{f}} \frac{1}{\tau^{2}} \frac{d \tau}{d t}=-\frac{1}{G_{m}} \frac{d \tau}{d t}-3^{\frac{m+1}{2}} G \tau^{n}
$$

This ordinary differential equation can be integrated analytically for integer $n>1$, yielding a polynomial equation for $\tau(t)$. For $n=2,3$, which are of relevance to many materials, the polynomials can be solved analytically. Thus, we have obtained an approximate closed form solution for the interfacial shear stress versus time under conditions of full relaxation of the matrix tensile stress. Predictions of the slip length versus time are compared with those obtained from the full differential equations of Du and McMeeking in Figure 4, and it is evident that the agreement is reasonable. In particular, our approximation captures the appropriate time scale quite accurately. We also note that the results of $\mathrm{Du}$ and McMeeking are not some simple power law of time, and our analytic result indicates the competition of two different powers.

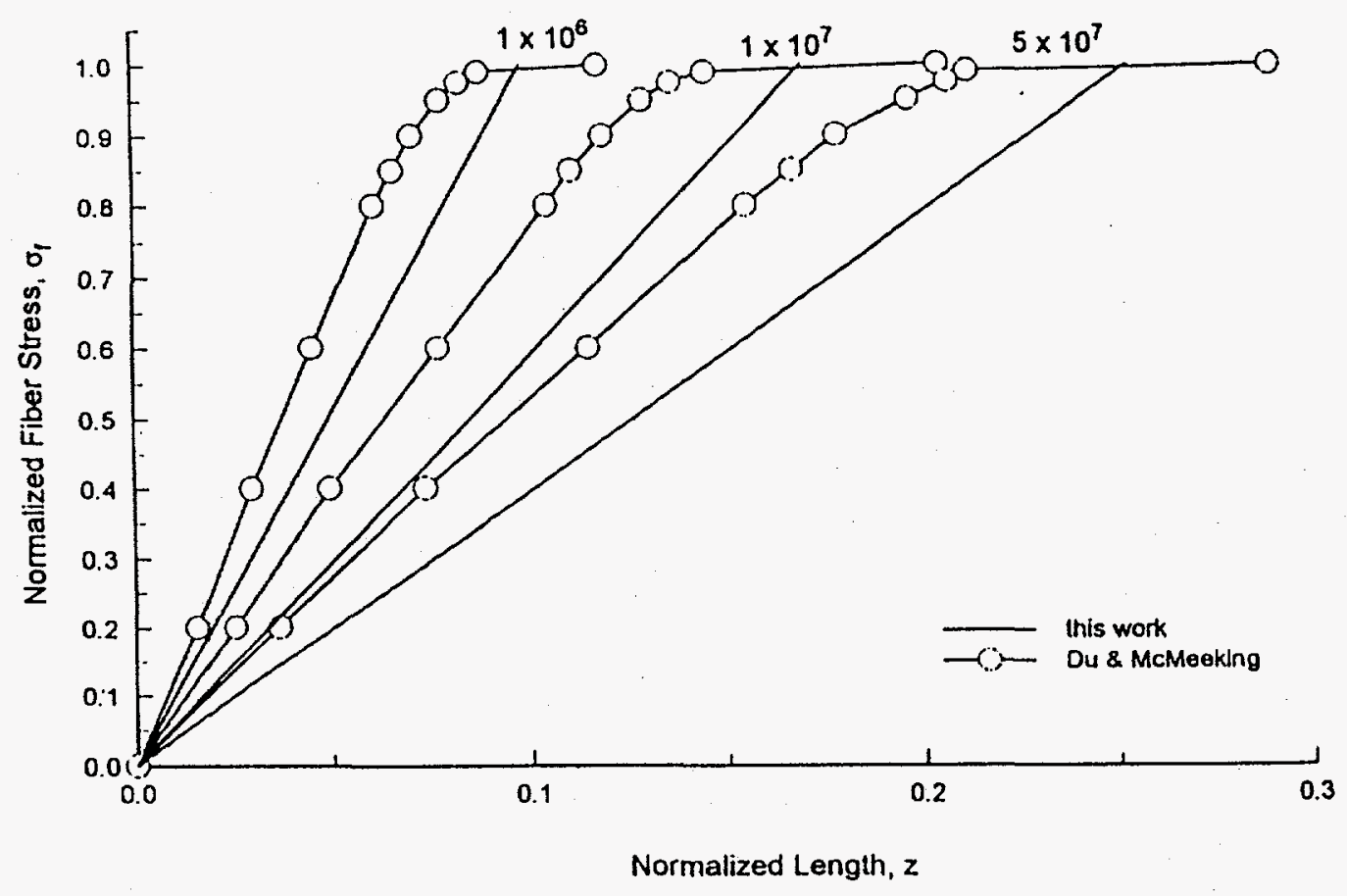

Figure 4. Axial fiber stress recovery around a break at $z=0$ for various dimensionless times $\mathrm{GE}_{\mathrm{f}} \sigma_{\mathrm{c}}{ }^{\mathrm{n}-1} \mathrm{t}$ for $\mathrm{n}=3$ as predicted by the model of $\mathrm{Du}$ and McMeeking (open symbols) and by the present analytic model (lines only). 
Returning to the composite as a whole, as a first brush at seeing the basic degradation process one can simply consider that the shear stress $\tau$ appearing in the characteristic strength parameter $\sigma_{\mathrm{c}}$ is merely a function of time as obtained above. As $\tau$, and hence $\sigma_{c}$, decreases the composite strength (Eq. 13) decreases and ultimately the strength reaches the level of the applied load and failure occurs. This is the present manner in which fatigue behavior of CMCs is understood, because a major fatigue mechanism at low temperatures is simply interface wear and a concomitant decrease in $\tau$ with cycles [11]. Given a form for $\tau(t)$, then, the failure time can then be estimated directly.

The above simple estimate is incorrect for several reasons. First, the value of $\tau$ decreases around any individual fiber only once that fiber breaks, and hence in a real composite there is, at any instant of time, a broad spectrum of $\tau$ values that depends on the history of the fiber breakage. Second, the ultimate strength expression given previously is predicated on the existence of only a few breaks per characteristic length $\delta_{\mathrm{c}}$. Since $\delta_{\mathrm{c}}$ now depends on time, it is possible that this condition is violated during the damage evolution. To investigate these features in detail has, to date, been prohibitively difficult analytically and so we will utilize numerical simulations of composite failure to study this overall degradation mode. The numerical simulations are based on the Global Load Sharing model developed and described by the Curtin in several recent publications [12], and are rather straightforward but will not be discussed here.

Using the above response of the interfacial shear stress, we have simulated composite creep and failure using the numerical model derived previously. The simulation proceeds as follows. An initial load is applied, and instantaneous fiber breaks at weak defects along the fibers are introduced to produce the initial starting state of damage and strain in the composite at the chosen applied load. Time is then incremented and the slip along the interface near existing broken fibers is updated according to $\tau(t)$. The reduced slip increases the stress on the other fibers which then break at a sequence of times $t_{i}$ and each begins interfacial relaxation following the function $\tau\left(t-t_{j}\right)$. The cumulative effect of slip and fiber damage determines the creep strain (which does not include the explicit fiber creep contribution established in Sec. 2.1 above, however), and failure occurs quite naturally when the stress on the remaining fibers exceeds their collective strength.

Results for strength versus time for two cases representative of Hi-Nicalon fibers in a matrix with $n=2,3$ as creep exponents are shown in Figure 5. The strength decreases very slowly with time, the behavior being roughly a power law behavior. The time scale for this relaxation ( $10^{7}$ seconds and larger) is rather larger than the tensile creep time scales obtained in Sec. 2.1, thus validating the assumption that the matrix tensile stresses have been relaxed by the time the shear creep mechanism becomes important. The degradation by shear creep is a rather long-time process but provides an absolute upper bound to the composite lifetime for tensile failure.

Since creep load transfer is so slow in the Siliconized SiC matrix material, the above degradation mechanism does not play an important role over the time scales required to obtain $1 \%$ tensile creep strain. We have therefore not performed any calculations for more specific materials. 


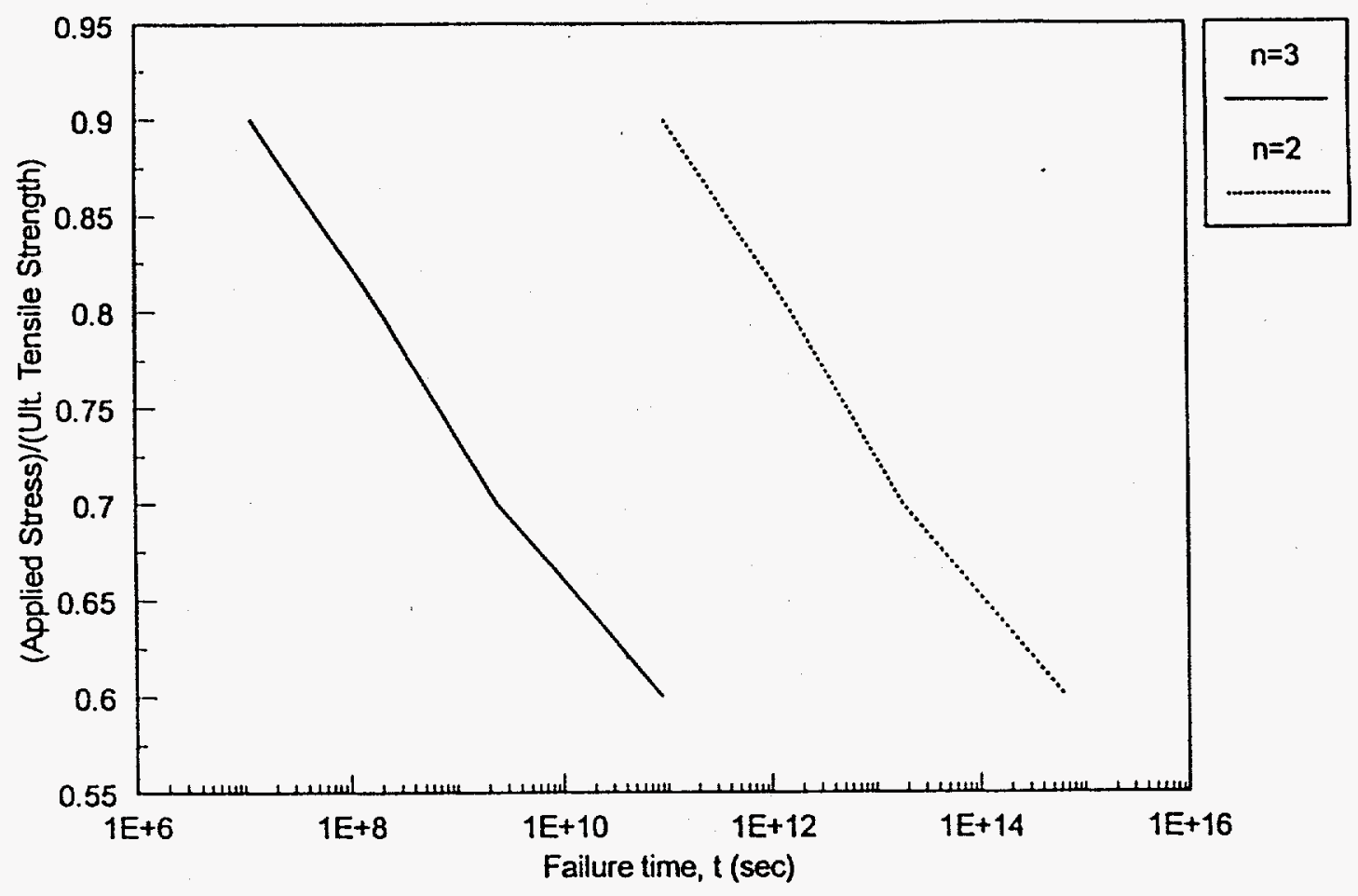

Figure 5. Time to failure by interfacial/matrix shear creep versus applied stress, normalized by the ultimate tensile strength, for a Hi-Nicalon fiber and a melt-infiltrated matrix with creep exponents $n=2,3$.

\subsection{Composite Failure by Fiber Strength Degradation}

High strength ceramic fibers are known to undergo strength loss at high temperatures and under loads. The issue addressed here is how the strength loss of individual fibers leads to overall composite failure in time under load. While experimental data by DiCarlo et al. [7] clearly demonstrates the trends in strength loss with variations in load, temperature, and atmosphere, the actual physical mechanisms of strength loss are not evident. Here, we consider two different potential mechanisms for accounting for strength loss and use these models to predict the failure of possible Fossil Energy composites. The two mechanisms are (i) slow crack growth from pre-existing flaws and (ii) creep damage development. The adjustable parameters arising in the models of these two mechanisms can be selected to match observed strength degradation on individual fibers and then the model forms are used in predicting composite behavior.

The important issue in determining composite failure is the strength loss of the fibers over the critical gauge length $\delta_{c}$, rather than the strength loss found in laboratory tests at a convenient testing gauge length $\mathrm{L}_{\mathrm{O}}$. Considering composite failure thus requires understanding both strength degradation and gauge length effects simultaneously. The 
models for fiber degradation consider the gauge length effects explicitly and therefore provide a means for relating laboratory data to expected composite performance.

\subsubsection{Failure by Slow Crack Growth in Fibers}

A crack in a brittle ceramic can undergo steady growth in the presence of an applied load and an embrittling environment. Such flaw growth is generally represented by a crack growth rate versus the stress intensity $\mathrm{K}$ prevailing at the crack tip of the form

$$
\frac{d c}{d t}=A K^{\beta}
$$

Here, $\mathrm{K}=\mathrm{Y} \sigma_{\mathrm{app}}(\mathrm{t}) \mathrm{c}^{1 / 2}$ is the stress intensity and $\sigma_{\mathrm{app}}(\mathrm{t})$ is the "applied" stress on the flaw at time $\mathrm{t}$. The flaw grows until $\mathrm{K}=\mathrm{K}_{\mathrm{ic}}$, at which point fast-fracture occurs. Applying this to individual fibers of gauge length $L_{0}$, we recognize that the initial largest flaw size $c_{0}$ in the fiber is also the flaw that determines the initial, or fast-fracture, tensile strength $\sigma_{0}$ of the fiber, through the relationship $\mathrm{K}_{\mathrm{ic}}=\mathrm{Y}_{0} \mathrm{c}_{\mathrm{o}}{ }^{1 / 2}$. Starting with a flaw of size $\mathrm{c}_{0}$, then, and under a time-dependent load we shall call $T(t)$, integrating the crack growth rate in time leads to a flaw size $c(t)$ and an associated fiber strength $\sigma(t)$ given by

$$
\sigma(t)=\left[\sigma_{0}(t)^{\beta-2}-\left(\frac{\beta}{2}-1\right)\left(A Y^{2} \pi K_{I c}^{\beta-2}\right) \int_{0}^{t} d t^{\prime} T\left(t^{\prime}\right)^{\beta}\right]^{\frac{1}{\beta-2}}
$$

For a single fiber of length $L_{0}$ and fast-fracture strength $\sigma_{0}$ tested in a single fiber tension test at a constant tensile load $\sigma_{\mathrm{app}}$, the time to failure $t_{\mathrm{f}}$ is determined as the time at which the fiber strength is equal to the applied load, $\sigma\left(t_{f}\right)=\sigma_{a p p}$, leading to the well-known time to failure [13]

$$
t_{f}=\left[\left(\frac{\beta}{2}-1\right)\left(A Y^{2} \pi K_{l c}^{\beta-2}\right)\right]^{-1}\left[\frac{\sigma_{o}^{\beta-2}}{\sigma_{a p p}^{\beta}}-\frac{1}{\sigma_{a p p}^{2}}\right]
$$

In the composite, the fibers experience a time-varying load $T(t)$ which arises from the load transfer from previously failed fibers being cast onto the remaining fibers. $T(t)$ is proportional to the strain on the unbroken fibers, and hence the composite strain. Also, there exists a distribution of initial fiber strengths as represented by the Weibull population and in the composite it is the strength around the characteristic stress $\sigma_{c}$ that is important. If under quasistatic tension the number of fiber failures per unit length $\delta_{\mathrm{c}}$ at stress $\sigma$ is given by the usual Weibull expression $\left(\sigma / \sigma_{\mathrm{C}}\right)^{\mathrm{m}}$ then, under a general time-varying load, the number of fiber failures per length $\delta_{\mathrm{c}}$ at stress $\sigma$ and time $t$ is given by the "damage parameter"

$$
\tilde{\rho}(\sigma, t)=\left[\sigma(t)^{\beta-2}+\left(\frac{\beta}{2}-1\right)\left(A Y^{2} \pi K_{l c}^{\beta-2}\right) \int_{0}^{t} d t^{\prime} T\left(t^{\prime}\right)^{\beta}\right]^{\frac{m}{\beta-2}} \frac{1}{\sigma_{c}^{m}}
$$


Overall equilibrium between the applied stress, the broken but sliding fibers, and the unbroken fibers then dictates that, at any instant of time, the total damage $\tilde{\rho}$ and the stress $T$ must satisfy the relationship

$$
\sigma_{a p p}=\frac{f \sigma_{c}}{\tilde{\rho}}\left[1-e^{-\bar{\rho} T / \sigma_{c}}\right]
$$

This form is a constitutive law for the composite, because $T$ is proportional to the composite strain, and is slightly more accurate than the expression used in the creep modelling (Sec. 2.1, Eq. 4 with $T=\sigma_{f}$ ). Under constant loading ( $\sigma_{\text {app }}$ fixed in time), Eq. 27 combined with the damage parameter evolution of Eq. 26 represents an integral equation for the time varying stress $T(t)$. Unfortunately, this equation cannot be solved analytically, although some progress on a related problem of fiber bundles with no matrix has been studied by McCartney and Kelly [14]. Numerical solutions to the integral equation are easy to obtain, however, and give the time dependent stress $T(t)$ and composite strain $\mathrm{T}(\mathrm{t}) / \mathrm{fE}_{\mathrm{f}}$. The failure time $\mathrm{t}_{\mathrm{f}}$ is reached when there are no solutions to Equations 26 and 27 - i.e. enough damage has formed that the damaged fiber bundle can no longer support the applied stress. The time scale for failure is normalized by the underlying time

$$
t_{c}=\left(\frac{\beta}{2}-1\right)\left(A Y^{2} \pi K_{1 c}^{\beta-2} \sigma_{c}^{2}\right)
$$

and the stress $\mathrm{T}$ is normalized by the characteristic stress $\sigma_{\mathrm{c}}$.

Because the initial applied stress sets an initial slip length $\delta=r \sigma_{a p p} / \tau$, and because the composite damage evolution is controlled by failures in the fibers over this length scale, the best time scale characteristic of the failure process in the composite is the time required to fail a "typical" individual fiber of length $\delta$ under stress $\sigma_{\text {app }}$. Weibull scaling of the fiber strength with length implies that the typical initial fiber strength $\sigma_{\delta}$ at this length can be expressed as $\sigma_{\delta}=\sigma_{o}\left(L_{o} / \delta\right)^{1 / m}$. Thus, the time scale for fiber failure at this length, $t_{\delta}$, is given by Eq. 25 but with the substitution of $\sigma_{\delta}$ for $\sigma_{0}$ :

$$
t_{\delta}=t_{c}\left[\frac{\hat{\sigma}_{\delta}^{\beta-2}}{\hat{\sigma}_{a p p}^{\beta}}-\frac{1}{\hat{\sigma}_{a p p}^{2}}\right]
$$

where the stresses are all normalized by the characteristic fiber strength $\sigma_{\mathrm{c}}$. The composite failure time is generally related to the characteristic time $t_{\delta}$ more closely than to any other time scale. Examples of the evolution of strain and failure in a ceramic composite for various values of $\beta$, with $m=5$ and at an applied stress of one-half of the tensile strength, are shown versus time normalized by $t_{\delta}$ in Figure 6 .

Considering all of our results for failure time obtained from integrating Eqs. 26 and 27 for combinations of the key parameters $\beta$ and $\mathrm{m}$, we have found an empirical relationship between the time to failure of the composite and the characteristic time $t_{\delta}$. Using this empirical relation, we have abtained a relationship between the composite 


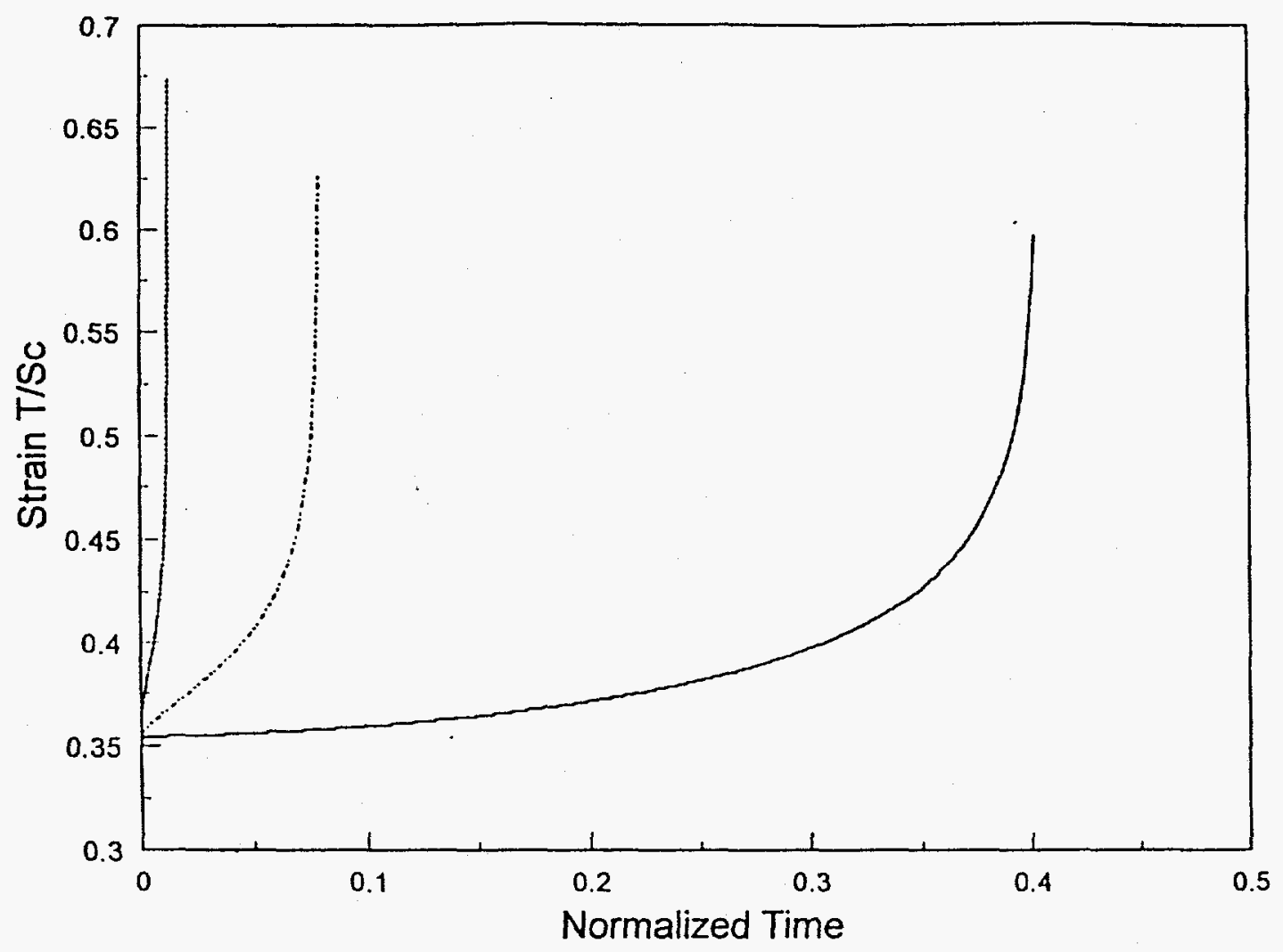

Figure 6. Normalized composite strain $T / \sigma_{c}$ versus normalized time $t / t_{\delta}$ for fibers degrading by the slow crack growth mechanism, for fibers of Weibull modulus $\mathrm{m}=5$ and a slow crack growth exponent $\beta=5$ (longest life), 10, 15 (shortest life).

failure time $t_{f}\left(\right.$ composite) and the time to failure $t_{f}\left(\right.$ fiber; $\left.L_{0}, \sigma_{a p p} / f\right)$ of a single typical fiber of gauge length $L_{o}$ tested at the stress $\sigma_{\text {app }} / f$ which has the form

$$
\frac{t_{f}(\text { composite })}{t_{f}\left(\text { fiber } ; L_{o}, \sigma_{a p p} / f\right)}=\left[\left(5 \frac{\hat{\sigma}_{a p p}}{f}\right)^{\frac{1}{m}} \hat{\sigma}_{o}\right]^{-(\beta-2)}
$$

where the stresses are normalized by $\sigma_{c}$, as indicated by the carats over the stresses. This relationship holds for applied stresses below about $70 \%$ of the fast-fracture strength. 
Prediction of composite life is thus obtainable quite simply and rapidly from experimental data on fibers tested in the laboratory, independent of many other details of the failure process.

As an example, we consider the Hi-Nicalon fiber composite under a temperature of $1200 \mathrm{C}$. The stress-rupture data for Hi-Nicalon in air and argon at this temperature has been obtained by DiCarlo et al. in the form of a "Larson-Miller" plot for stress versus a dimensionless parameter related to the logarithm of the fiber life, and is reproduced in Figure 7. The slope of the life versus stress curve determines the value of $\beta=5$. We take the fast-fracture strength at temperature to be $\sigma_{0}=2000 \mathrm{MPa}$ with a Weibull modulus of $\mathrm{m}=5$. The interfacial sliding resistance is taken as $\tau=10 \mathrm{MPa}$, and the longitudinal fiber volume fraction is $f=0.2(2-\mathrm{d}$ material with $40 \%$ total volume fraction). The value of the characteristic strength $\sigma_{\mathrm{C}}$ is then $3170 \mathrm{MPa}$ and the fast fracture composite strength is predicted to be $453 \mathrm{MPa}$, using the various definitions from Section 2.1 .

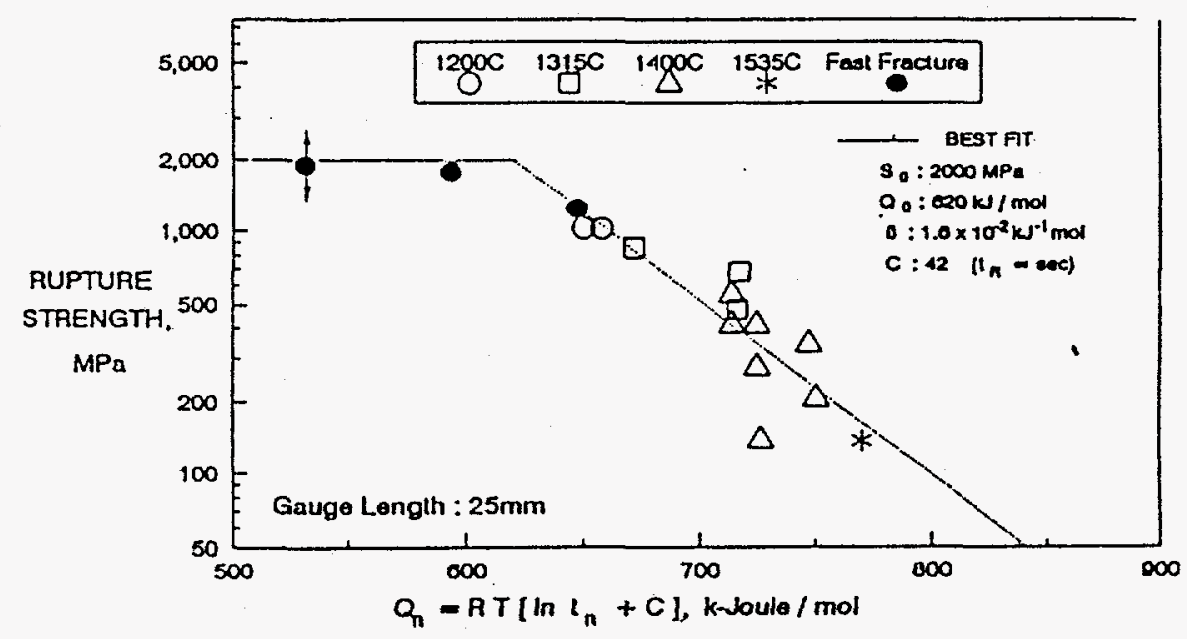

Figure 7. Stress rupture data on Hi-Nicalon fibers, in the form of applied stress versus logarithm of rupture time, from DiCarlo et al. (Ref. 7).

Now consider the composite under an applied load of $150 \mathrm{MPa}$, presumed above the matrix cracking limit for this system. The effective stress on the fibers is 150 $\mathrm{MPa} / 0.2=750 \mathrm{MPa}$. Inserting these values into the above equation yields the prediction of a composite life 3.6 times longer than a typical individual fiber. From the single fiber data at stress $750 \mathrm{MPa}$, the fiber life is approximately 142 hours and hence the composite lifetime is 511 hours.

At an applied load of $100 \mathrm{MPa}$ (still assuming matrix cracking), the effective fiber stress is $500 \mathrm{MPa}$ and the ratio of composite to fiber life is 4.6. Note that the ratio depends on the applied load; the life of the composite is comparatively longer at lower loads. From the data of DiCarlo et al. the typical fiber life at this stress is 1072 hours, and hence the composite life is 4930 hours. 
The high temperature fast-fracture strength statistics of the Hi-Nicalon fibers has not been made available to us, and hence our numbers here are estimates. For demonstration, however, we emphasize the important role of the fiber Weibull modulus in determining composite life. If the Weibull modulus is decreased to $m=3$, but for the same fast-fracture strength of $2000 \mathrm{MPa}$, then the characteristic strength relevant to failure in the composite is actually rather higher, $\sigma_{c}=3992 \mathrm{MPa}$. Carrying through the calculation of composite life to single fiber life at stress $150 \mathrm{MPa}$ then yields a factor of 8.5 increase in life; i.e. the composite life is 1200 hours. At $100 \mathrm{MPa}$ the increase in life is a factor of 12.8 such that the predicted life is 13,700 hours. The increase in predicted life comes about because at the short characteristic gauge length relevant to failure in the composite, the fiber is much stronger than at the fixed $1 "$ length. Thus, the flaw sizes are smaller and their growth in time is much slower, leading to a longer composite lifetime than one would expect based on the fiber life at the 1 " gauge length.

If the Hi-Nicalon fiber strength is lower than estimated, then the lifetime is not necessarily shorter. Taking the 1 " strength to be only $\sigma_{0}=1750 \mathrm{MPa}$ with the original $\mathrm{m}=5$ leads to $\sigma_{\mathrm{c}}=2837 \mathrm{MPa}$. At the applied stress of $150 \mathrm{MPa}$, the ratio of composite to single fiber life is still 3.6. The procedure of normalizing by the fiber life eliminates some of the sensitivity to actual fiber strength. Note, however, that if the fibers are damaged by processing then the in-situ strength and its degradation are not related to the strengths measured on single fibers in the laboratory. Any prediction of composite life based on exsitu fiber strength is then very qualitative. Assessment of post-processing, in-situ fiber strengths by, for instance, fracture mirrors would allow the present theory to be applied by using the slow crack growth parameters $A$ and $\beta$ obtained ex-situ to determine the strength degradation of the processing-induced flaws of the in-situ fiber.

\subsubsection{Failure by Fiber Creep Damage}

The strength degradation of many fibers can be adequately described by the empirical model of Coleman in which the probability of failure of a fiber of length $L$ and tested at stress $\sigma$ is given by [15]

$$
P(l, \sigma)=1-\exp \left[\frac{L}{L_{o}}\left(\int_{0}^{t} \frac{d t^{\prime}}{t_{o}}\left(\frac{\sigma}{\sigma_{o}}\right)^{\beta}\right)^{m^{*}}\right]
$$

In Eq. 31, the reference parameters are such that $t_{0}$ is the time to failure of a fiber of length $L_{0}$ which has been held at stress $\sigma_{0}$. The exponent $\beta$ is the Weibull shape parameter for time and $m^{*}=m /(\beta+1)$ where $m$ is the usual Weibull modulus for strength. The assumption in the Coleman model is that during time at load damage forms ("creep" damage) and accumulates, leading to strength decrease. The initial flaws in the fiber play no role in this damage mechanism, and are assumed to be unchanging with time. Thus, the above model becomes appropriate at time scales over which the new creep damage is sufficiently large that the fiber strength is reduced below its initial value.

In the creep damage regime, one can express the characteristic fiber life at stress

$\sigma_{a p p}$ and length $L_{o}$ as 


$$
t_{L_{b}}\left(\sigma_{a p p}\right)=t_{o}\left(\frac{\sigma_{a p p}}{\sigma_{o}}\right)^{-\beta}
$$

Laboratory data on fiber lifetime follow an identical relationship, and the power-law exponent $\beta$ can be clearly derived from such experimental data (see Fig. 7 for data on HiNicalon fibers at various temperatures and applied loads).

The degradation in composite strength caused by fiber strength loss following the Coleman model above has been studied extensively in recent work by Ibnabdeljalil and Phoenix [15] by a time-dependent generalization of the Global Load Sharing simulation model of Curtin [12] We utilize their results directly here, and have performed additional numerical simulations for the specific cases relevant to fiber with low values of $\beta$, as indicated in Figure 5.

Ibnabdeljalil and Phoenix have defined the characteristic time $t_{c}$, which is the single fiber lifetime of a length $\delta_{\mathrm{c}}$ tested at stress $\sigma_{\mathrm{c}}$ and follows from the above Weibull scaling as

$$
t_{c}=t_{o}\left(\frac{\sigma_{c}}{\sigma_{o}}\right)^{-\beta}
$$

where the Weibull relationship between strengths and lengths of $\sigma_{\mathrm{c}} / \sigma_{\mathrm{O}}=\left(\mathrm{L}_{\mathrm{o}} / \delta_{\mathrm{c}}\right)^{1 / \mathrm{m}}$ has been used. The composite lifetime at stress $\sigma$ has been obtained by simulation studies, and is found to follow the simple form

$$
t_{f}(\sigma)=t_{c}\left\{\left(\frac{\sigma_{a p p}}{\sigma_{u t s}}\right)^{-\tilde{\beta}}\right.
$$

where $\sigma_{\mathrm{uts}}$ is the tensile strength as given, in normalized form, by Eq. 13. The exponent $\tilde{\beta}$ is related to the single fiber life exponent $\beta$ by a linear relationship depending on the fiber Weibull modulus $\mathrm{m}$, and $\xi \approx(\ln 2)^{-1 / \mathrm{m}^{*}}$. For $\mathrm{m}=5$, we have found $\bar{\beta}=1.15 \beta+0.356$ but a general asymptotic relationship is

$$
\bar{\beta}=\beta+\frac{\beta}{m+1}
$$

Writing $\sigma_{\mathrm{uts}}=\mathrm{f} \varphi(\mathrm{m}) \sigma_{\mathrm{c}}$ where $\varphi(\mathrm{m})$ is given in Eq. 13, and normalizing the composite failure time $t_{f}$ by the single fiber life at length $L_{o}$ and stress $\sigma$, we finally obtain the ratio of composite life to laboratory fiber life given by

$$
\frac{t_{f} \text { (composite) }}{t_{f}\left(\text { fiber } ; L_{o}, \sigma_{a p p} / f\right)}=\xi \varphi^{\tilde{\beta}}\left[\left(\frac{\hat{\sigma}_{a p p}}{f}\right)^{\frac{1}{m}} \hat{\sigma}_{o}\right]^{-(\beta+1)}
$$

This result is extremely similar in structure to that obtained from the Slow Crack Growth model for fiber strength degradation studied in 3.3.1, i.e. Eq. 30 above, in spite of the difference in degradation mechanism. Such a similarity is good, because we hope not to need the precise fiber degradation mechanism to determine the composite strength; we merely wish to relate laboratory fiber and composite lifetimes. The differences between Eq. 36 and Eq. 30 are that the mumerical prefactor is slightly different and the exponent is $\beta-2$ in Eq. 30 and $\beta+1$ in Eq. 36. 
Specific predictions for the composite life versus applied stress from the numerical simulations for Hi-Nicalon fibers at $1200 \mathrm{C}$ are shown in Figure 8. Also shown is the data of DiCarlo et al. on single fibers at the same effective stress, and the ratio of the two results is given approximately by Eq. 36 above. At a stress of $150 \mathrm{MPa}$, the composite lifetime is 17.3 times longer than the individual fibers at length $\mathrm{L}_{\mathrm{o}}$ and at $100 \mathrm{MPa}$ the composite life is a factor of 28 longer. These results are comparable to, but higher than, those obtained from the Slow Crack Growth model. One reason for the predicted longer life is that since the Coleman model does not allow the pre-existing flaws to grow, the strength is only reduced once the creep damage has had sufficient time to become strength-controlling. Thus, in Figure 8 the composite lifetime just slightly below the fastfracture strength is a finite value of about 2.8 hours. At lower loads this effect should become less important, however.

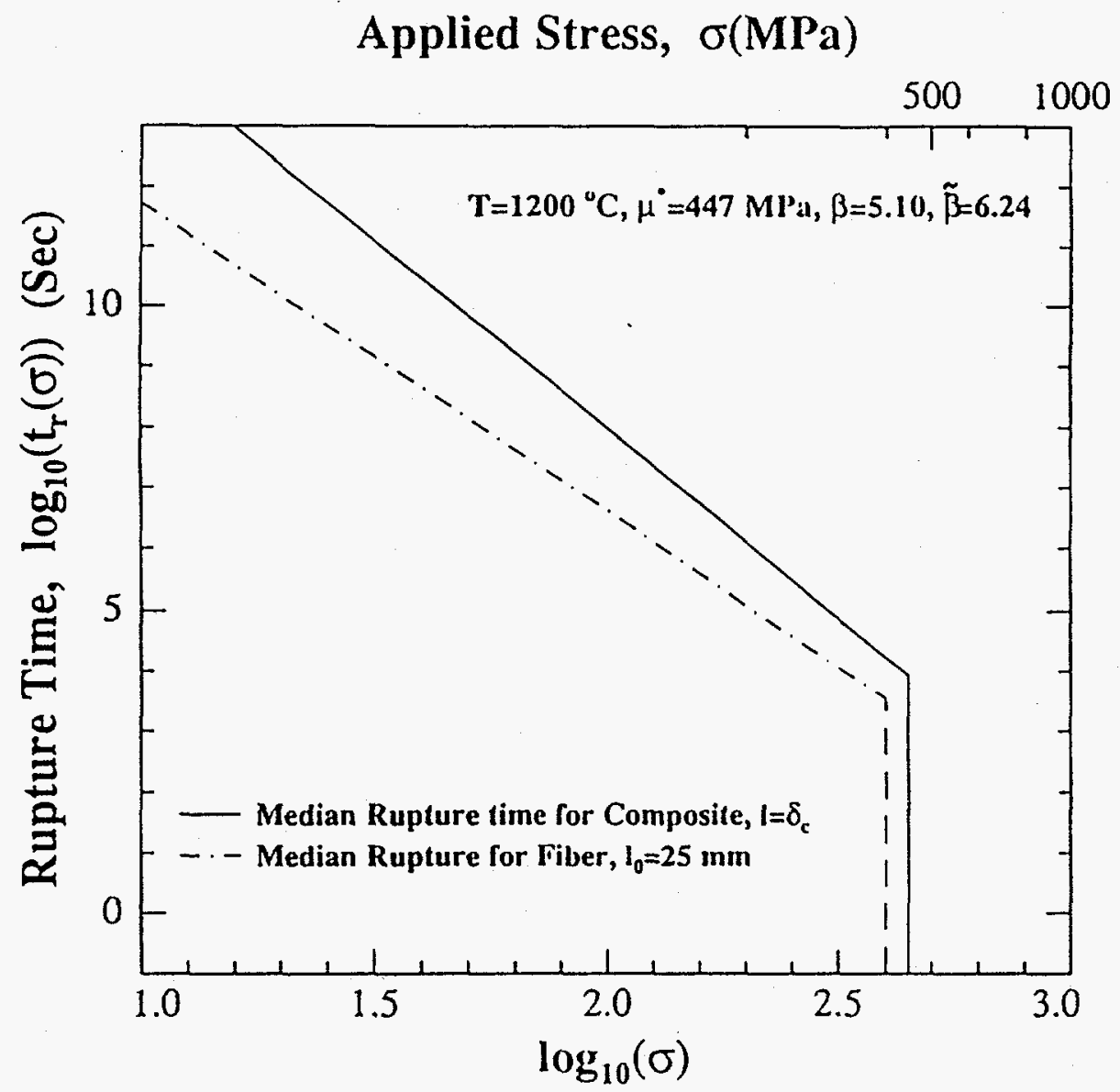

Figure 8. Predicted composite and single fiber stress rupture for Hi-Nicalon fibers at $1200 \mathrm{C}$ versus applied stress. Generally, the composite lives atleast an order of magnitude longer than the laboratory fiber tested at the same effective stress. 


\section{Discussion and Summary}

We have investigated three potential damage evolution modes in ceramic matrix composites:

(i) composite creep deformation which leads to stress transfer between matrix and fibers;

(ii) matrix/interface shear creep which decreases the load carried by damaged fibers;

(iii) fiber strength degradation in time by creep and slow crack growth mechanisms.

The second damage mode is demonstrated to be a long-term failure mode in materials which do not have fiber strength degradation, and is the least important of the three modes considered here. The other two degradation modes lead to different types of failure: creep-limited and rupture-limited "failures". The interplay between them may be complicated; we have provided models to calculate the creep and rupture lives separately, and the importance of each mode depends on the loading conditions. If matrix cracking is induced, then creep load transfer ceases and the fiber degradation mechanism controls failure (in the absence of debilitating oxidation of the interfaces) with a potential long-term effect of the shear creep (mode (ii) above). If matrix cracking is not induced, then the load transfer from matrix to fibers delays the onset of fiber strength degradation.

We have applied the above models to the special case of 2-d Hi-Nicalon fibers in a Melt-infiltrated matrix composite. We can now make the following more general comments based on those results. If the initial loads are such that the matrix does not crack, or the load is applied sufficiently slowly that the matrix creeps enough to avoid cracking, then the fibers do not experience the maximum load $\sigma_{\mathrm{app}} / \mathrm{f}$ over the full stress history. Because the fiber strength degradation rate is very sensitive to stress level (see Figure 7), the actual fiber degradation will be much less than the estimates made here. A comparison of the lower bound for the stress rupture life of 511 hours at $150 \mathrm{MPa}$ and the upper bound $1 \%$ creep life of 675 hours at $140 \mathrm{MPa}$ suggests that the Hi-Nicalon/Meltinfiltrated composite is primarily creep-limited rather than rupture limited. Similarly, at the lower applied stress of $100 \mathrm{MPa}$ the lower-bound stress rupture life of 4930 hours is approximately the same as the upper bound $1 \%$ creep life. It would be possible to utilize the input from the creep evolution equations as a time-dependent load on the fibers to quantify the stress rupture more fully (and in fact combining the damage-evolution integral equation with the creep stress evolution is also possible).

The above considerations indicate that this particular composite system is creeplife limited rather than fiber-strength limited for the particular material parameters used here. Decreasing the matrix creep rate will further increase the creep life and decrease the rate of fiber strength degradation at the same time; this is thus a very desirable design goal, as long as the matrix creep rate remains slower than that of the fibers. A parametric study of the interplay between creep deformation and stress rupture under a time-varying (creep) fiber load could be carried out if such a scheme is deemed necessary.

No calculations have yet been carried out for creep in CVI-SiC matrix materials [16] because no reliable information on the creep rate of CVI-SiC has been made available. Discussions with Dr. Jim DiCarlo suggest that the CVI-SiC is fairly creep resistant, and may creep more slowly than the current generation of fibers. Such a 
situation would drive early matrix cracking, and then accelerated creep (by the fibers) and fiber degradation by stress rupture. For sufficiently slow matrix creep rates, the stress rupture life would then be identical to that estimated above because the stress rupture results are independent of the nature of the matrix. The life of Hi-Nicalon fiber composites at stresses of 100-150 MPa may thus be limited, whether via creep or rupture, to lifetimes of 500-5000 hours, even in the absence of the known oxidative embrittlement problems.

Specific data on CVI-SiC or Melt-infiltrated matrix creep rates may, however, lead to very slow creep load transfer which does not drive matrix cracking or faster fiber stress rupture. In the ideal case of perfectly matched creep rates, the stress rupture life can be estimated from above by assuming an "applied stress" of $E_{f} \sigma / E_{c}$ on the fibers; the creep life is obtained from the fiber data at the same load. For the Melt-infiltrated/Hi-Nicalon material at $150 \mathrm{MPa}$, this limit would lead to a ratio of composite life to single fiber life of 9.5 , but with the single fiber life evaluated at the stress of only $150 \mathrm{MPa}$, rather than 750 $\mathrm{MPa}$ in the case of complete load transfer. The composite life would then be $1.3 \times 10^{6}$ hours; such a large time results from the very long fiber life at such a low stress. The $1 \%$ creep life is obtained directly from the fiber creep data, and yields a lifetime of 41,700 hours, which is again quite long because of the low stress on the fibers. [Since the fiber experiences creep hardening, the matrix would need to exhibit a similar behavior for this simple calculation to be precise]. These estimates again indicate creep life as the limiting factor even under the "ideal conditions" of no fiber/matrix load transfer over time. However, they also suggest that even with current Hi-Nicalon fibers it is possible that matrices could be designed to obtain closely-matched creep rates and give long composite lifetimes. Damage tolerance will not be improved by this strategy, however; matrix damage leading to the load being borne by the fibers will cause fiber strength degradation at the rates predicted here, independent of the creep rates, and thus the lifetime will be roughly equal to the rupture times calculated here.

The predictive models described here can be applied to determine the timedependent deformation of any potential composite materials, given the constituent property information. Hence, the likelihood of achieving design goals with the current constituent materials, or modified/optimized materials, can easily be assessed. Further calculations and predictions on Fossil Energy program materials can be carried out, using the models and formulas given above, if knowledge of the underlying constituent material performance is known. The most needed input at present is the creep behavior of the CVI-SiC. However, it may also be possible to use the present creep models to backcalculate the matrix creep behavior from the measured composite response on unidirectional materials.

The micromechanical models developed here describe the degradation and creep of unidirectional ply-level lamina. The results from these models can thus also serve as input to component-level life prediction methodologies, such as the MRLife ${ }^{\mathrm{TM}}$ code developed by the Materials Response Group at Virginia Tech, to complete the connection between constituent material properties and durability of actual component structures to be utilized in Fossil Energy applications. 


\section{References}

1. P.G. LaHaye and M.R. Bary, Externally Fired Combustion Cycle (EFCC) A DOE Clean Coal Project: Effective Means of Rejuvenation for Older Coal-Fired Stations, Intl. Gas Turbine and Aeroengine Congress and Exposition, Paper \# 94-GT-483, ASME (New York, 1994).

2. R.R. Judkins, D.P. Stinton, R.G. Smith, E.M. Fischer, J.H. Eaton, B.L. Weaver, J.L. Kahnke, and D.P. Pysher, Development of Ceramic Composite Hot-Gas Filters, Intl. Gas Turbine and Aeroengine Congress and Exposition, Paper \# 95-GT-305, ASME (New York, 1995).

3. M. McLean, Creep Deformation of Metal Matrix Composites, Composites Science and Technology 23, 37 (1985).

4. C.H. Weber, Z.Z. Du, and F.W. Zok, High Temperature Deformation and Fracture of a Fiber Reinforced Titanium Matrix Composite, Acta Metallurgica, to appear in 1995.

5. W.A. Curtin, Theory of the Mechanical Properties of Ceramic Matrix Composites, J. American Ceramic Soc. 74, 2837 (1991).

6. J.M. Duva, W.A Curtin, and H.N.G. Wadley, An Ultimate Tensile Strenghth Dependence on Processing for Consolidated Metal Matrix Composites, Acta Metallurgica 43, 1119 (1995).

7. J.A. DiCarlo, H.M. Yun, G.N. Morscher, and J.C. Goldsby, Models for the Thermostructural Properties of SiC Fibers, in High Temperature Ceramic-Matrix Composites II: Manufacturing and Materials Development, eds. A.G. Evans and R. Naslain, American Ceramic Society (Westerville, OH) 1995, p. 343.

8. S.M. Weiderhorn, D.E. Roberts, T.J. Chuang, and L. Chuck, Damage-enhanced Creep in a Siliconized Silicon Carbide: Phenomenology, J. Am. Cer. Soc. 71, 602 (1988).

9. Z.Z. Du and RM. McMeeking, Creep Models for Metal Matrix Composites with Long Brittle Fibers, J. Mechanics and Physics of Solids 43, 701 (1995).

10. A. Kelly and K.N. Street, Creep of Discontimuous Fibre Composites: 2. Theory for the Steady-State, Proc. Royal Society of London A328, 283 (1972).

11. A. G. Evans, F. W. Zok, and R. M. McMeeking, Fatigue of Ceramic Matrix Composites, Acta Met. Mater. 43, 859 (1995).

12. W.A. Curtin, Fiber Pullout and Strain Localization in Ceramic Matrix Composites, J. Mechanics and Physics of Solids 41, 35 (1993). W.A. Curtin and S.J. Zhou, Influence 
of Processing Damage on Performance of Fiber-Reinforced Composites, J. Mechanics and Physics of Solids 43, 343 (1995)

13. A. Kelly and N. MacMillan, Strong Solids, 3rd Edition, (Clarendon Press, Oxford, 1986).

14. A. Kelly and L.N. McCartney, Proc. Royal Society A374, 475 (1981).

15. M. Ibnabdeljalil and S.L. Phoenix, Creep Rupture of Brittle Matrix Composites Reinforced with Time-Dependent Fibers: Scalings and Monte Carlo Simulations, J. Mechanics and Physics of Solids 43, 897 (1995).

16. D.P. Stinton, A.J. Caputo, and R.A. Lowden, Synthesis of Fiber-Reinforced SiC Composites by Chemical Vapor Infiltration, Am. Cer. Soc. Bull. 65, 347 (1986). 


\section{Appendix - Distribution}

\section{CERAMIC COMPOSITES DISTRIBUTION}

3M COMPANY

Ceramic Materials Department

201-4N-01 3M Center,

St. Paul, MN 55144

M. A. Leitheiser

AIR PRODUCTS AND CHEMICALS

P.O. Box 538

Allentown, PA 18105

S. W. Dean

\section{ALLISON GAS TURBINE DIVISION}

P.O. Box 420

Indianapolis, IN 46206-0420

P. Khandelwal (Speed Code W-5)

R. A. Wenglarz (Speed Code W-16)

AMA RESEARCH \& DEVELOPMENT CENTER

5950 McIntyre Street

Golden, CO 80403

T. B. Cox

ARGONNE NATIONAL LABORATORY 9700 S. Cass Avenue

Argonne, IL 60439

W. A. Ellingson

J. P. Singh

ARGONNE NATIONAL

LABORATORY-WEST

P.O. Box 2528

Idaho Falls, ID 83403-2528

S. P. Henslee

\section{BABCOCK \& WILCOX}

Domestic Fossil Operations

20 South Van Buren Avenue

Barberton, $\mathrm{OH} 44023$

M. Gold
BRITISH COAL CORPORATION

Coal Technology Development Division

Stoke Orchard, Cheltenham

Glocestershire, England GL52 4ZG

J. Oakey

CANADA CENTER FOR MINERAL \&

ENERGY TECHNOLOGY

568 Booth Street

Ottawa, Ontario

Canada K1A OG1

R. Winston Revic

Mahi Sahoo

DOE

DOE OAK RIDGE OPERATIONS

P.O.Box 2001

Oak Ridge, TN 37831

Assistant Manager for

Energy Research and Development

DOE

DOE OAK RIDGE OPERATIONS

P. O. Box 2008

Building 4500N, MS 6269

Oak Ridge, TN 37831

M. H. Rawlins

DOE

OFFICE OF BASIC ENERGY SCIENCES

Materials Sciences Division

ER-131

19901 Germantown Road

Germantown, MD 20874-1290

H. M. Kerch

DOE

IDAHO OPERATIONS OFFICE

P. O. Box 1625

Idaho Falls, ID 83415

J. B. Malmo 
DOE

MORGANTOWN ENERGY TECHNOLOGY CENTER

P.O. Box 880

Morgantown, WV 26505

R. C. Bedick

D. C. Cicero

F. W. Crouse, Jr.

R. A. Dennis

N. T. Holcombe

W. J. Huber

T. J. McMahon

J. E. Notestein

DOE

OFFICE OF FOSSIL ENERGY

FE-72

19901 Germantown Road

Germantown, MD 20874-1290

J. P. Carr

DOE

OFFICE OF VEHICLE AND ENERGY R\&D CE-151 Forrestal Building

Washington, DC 20585

R. B. Schulz

DOE

OFFICE OF SCIENTIFIC AND TECHNICAL INFORMATION

P. O. Box 62

Oak Ridge, TN 37831

For distribution by microfiche as shown in DOE/TIC-4500, Distribution Category:

UC-114 (Coal Based Materials and

Components)
DOE

PITTSBURGH ENERGY TECHNOLOGY CENTER

P.O. Box 10940

Pittsburgh, PA 15236

A. L. Baldwin

G. V. McGurl

L. A. Ruth

T. M. Torkos

DOW CORNING CORPORATION

3901 S. Saginaw Road

Midland, MI 48686-0995

H. Atwell

EC TECHNOLOGIES

3614 Highpoint Drive

San Antonio, TX 78217

D. J. Kenton

ELECTRIC POWER RESEARCH

INSTITUTE

P.O. Box 10412

3412 Hillview Avenue

Palo Alto, CA 94303

W. T. Bakker

J. Stringer

\section{EUROPEAN COMMUNITIES JOINT} RESEARCH CENTRE

Petten Establishment

P.O. Box 2

1755 ZG Petten

The Netherlands

M. Van de Voorde

GA TECHNOLOGIES. INC.

P.O. Box 85608

San Diego, CA 92138

T. D. Gulden 
GEORGIA INSTITUTE OF TECHNOLOGY

Materials Science \& Engineering (0245)

Bunger-Henry Building, Room 276

Atlanta, GA 30332-0245

T. L. Starr

IDAHO NATIONAL ENGINEERING

LABORATORY

P. O. Box 1625

Idaho Falls, ID 83415

B. H. Rabin

LAVA CRUCIBLE-REFRACTORIES CO.

P.O. Box 278

Zelienople, PA 16063

T. Mulholland

LAWRENCE LIVERMORE NATIONAL

LABORATORY

P.O. Box 808, L-325

Livermore, CA 94550

W. A. Steele

LOS ALAMOS NATIONAL LABORATORY

P.O. Box 1663

Los Alamos, NM 87545

J. D. Katz

NATIONAL INSTITUTE OF STANDARDS AND TECHNOLOGY

U.S. Dept. of Commerce

Bldg. 220, Rm A215

Gaithersburg, MD 20899

S. G. Malghan

NATIONAL MATERIALS ADVISORY

BOARD

National Research Council

2101 Constitution Avenue

Washington, DC 20418

K. M. Zwilsky
OAK RIDGE NATIONAL LABORATORY

P.O. Box 2008

Oak Ridge, TN 37831

P. T. Carlson

N. C. Cole

R. R. Judkins

R. A. Lawson (8 copies)

E. L. Long, Jr.

D. P. Stinton

M. R. Upton

OFFICE OF NAVAL RESEARCH

Code 431, 800 N. Quincy Street

Arlington, VA 22217

S. G. Fishman

SANDIA NATIONAL LABORATORIES

Department 6211, MS 0710

Albuquerque, NM 87185

R. J. Buss

G. A. Carlson

A. G. Sault

SHELL DEVELOPMENT COMPANY

P.O. Box 1380

Houston, TX 77251-1380

L. W. R. Dicks

TENNESSEE VALLEY AUTHORITY

Energy Demonstration \& Technology

MR2N58A

Chattanooga, TN 37402-2801

C. M. Huang

THE JOHNS HOPKINS UNIVERSITY

Materials Science \& Engineering

Maryland Hall

Baltimore, MD 21218

R. E. Green, Jr. 
THE MATERIALS PROPERTIES COUNCIL. INC.

United Engineering Center

345 E. Forty-Seventh Street

New York, NY 10017

M. Prager

THE NORTON COMPANY

High Performance Ceramics Division

Goddard Road

Northborough, MA 01532-1545

N. Corbin

THE TORRINGTON COMPANY

Advanced Technology Center

59 Field St.

Torrington, CT 06790

W. J. Chmura

UNION CARBIDE CORPORATION

Linde Division

P.O. Box 44

175 East Park Drive

Tonawanda, NY 14151-0044

Harry Cheung

UNITED TECHNOLOGIES RESEARCH

CENTER

MS 24, Silver Lane

East Hartford, CT 06108

K. M. Prewo

\section{UNIVERSITY OF TENNESSEE}

Dept of Materials Science and Engineering

Knoxville, TN 37996-2200

Peter Liaw

\section{UNIVERSITY OF WASHINGTON}

Department of Materials Science and

Engineering

101 Wilson, FB-10

Seattle, WA 98195

T. G. Stoebe
VIRGINIA POLYTECHNIC INSTITUTE \& STATE UNIVERSITY

Department of Materials Engineering

Blackburg, VA 24601

W. A. Curtin

K. L. Reifsnider

WESTERN RESEARCH INSTITUTE

365 N. 9th Street

P.O. Box 3395

University Station

Laramie, WY 82071

V. K. Sethi

WESTINGHOUSE ELECTRIC CORPORATION

Research and Development Center

1310 Beulah Road

Pittsburgh, PA 15235

S. C. Singhal 
This report has been reproduced directly from the best available copy.

Available to DOE and DOE contractors from the Office of Scientific and Technical Information, P.O. Box 62, Oak Ridge, TN 37831; prices available from (423) 576-8401.

Available to the public from the National Technical Information Service, U.S. Department of Commerce, 5285 Port Royal Rd., Springfield, VA 22161.

This report was prepared as an account of work sponsored by an agency of the United States Government. Neither the United States Government nor any agency thereof, nor any of their employees, makes any warranty, expressed or implied, or assumes any legal liability or responsibility for the accuracy, completeness, or usefulness of any information, apparatus, product, or process disclosed, or represents that its use would not infringe privately owned rights. Reference herein to any specific commercial product, process, or service by trade name, trademark, manufacturer, or otherwise, does not necessarily constitute or imply its endorsement, recommendation, or favoring by the United States Government or any agency thereof. The views and opinions of authors expressed herein do not necessarily state or reflect those of the United States Government or any agency thereof. 